\title{
RESEARCH
}

\section{Deconstructing information structure}

\author{
Angelika Kratzer and Elisabeth Selkirk \\ uMass Amherst, us \\ Corresponding author: Angelika Kratzer (kratzer@umass.edu)
}

\begin{abstract}
The paper argues that a core part of what is traditionally referred to as 'information structure' can be deconstructed into genuine morphosyntactic features that are visible to syntactic operations, contribute to discourse-related expressive meanings, and just happen to be spelled out prosodically in Standard American and British English. We motivate two features, [FoC] and [G], and we track the fate of those features at and beyond the syntax-semantics and the syntaxphonology interfaces. [FoC] and [G] are responsible for two distinct obligatory strategies for establishing discourse coherence. A [G]-marked constituent signals a match with a discourse referent, whereas a $[\mathrm{FoC}]$-marked constituent invokes alternatives and thereby signals a contrast. In Standard American and British English [FoC] aims for highest prosodic prominence in the intonational phrase, whereas [G] lacks phrase-level prosodic properties. There is no grammatical marking of newness: The apparent prosodic effects of newness are the result of default prosody.
\end{abstract}

Keywords: Information structure; morphosyntactic features; focus; givenness; prosody; alternatives semantics; syntax-phonology interface; syntax-semantics/pragmatics interface

\section{Introduction}

Information structure, as the term is commonly used, covers concepts related to givenness, contrast, and topicality. Despite many years of research, there is no common ground on how to identify those concepts, what their place in grammar is, or whether there is any theoretical unity or value to them. Here we will set aside topicality and limit our discussion to givenness and contrast. ${ }^{1}$ We will build a case supporting the view that Standard American and British English has two syntactically well-motivated features triggering distinct discourse requirements related to givenness and contrast. One feature, Givenness marking ([G]-marking, Féry \& Samek-Lodovici 2006), signals that an individual, concept, or proposition has been mentioned before or is otherwise present in the context. The other feature, FoCus marking ([FoC]-marking), evokes alternatives to a mentioned individual, concept, or proposition, and thereby signals a contrast in the surrounding discourse. Mere newness remains unmarked.

Givenness and contrast have been discussed as categories of information structure at least since Chafe (1976). Rochemont (2016) has an in-depth discussion of givenness in the sense intended here and distinguishes it from kindred notions like presuppositionality, definiteness, repetition, and predictability. Following Rochemont, we capitalize Givenness whenever the targeted notion of givenness is the one responsible for the lack of prominence on content words under certain discourse conditions in Standard American and British English. In a similar vein, we use the spelling FoCus when the intended notion of

\footnotetext{
${ }^{1}$ For the autonomy of the 'topic-comment' ('theme-rheme') distinction, see Hajičová (1994), speaking for the Prague School more generally, see also Gundel (1988) and Gundel \& Fretheim (2004).
} 
focus is tied to the introduction of alternatives to signal a contrast. ${ }^{2}$ Crucially, FoCus needs to be distinguished from information focus ('newness focus'), which applies to expressions that merely present new information. As will be made clear in section 8 , the targeted notion of FoCus is a very general kind of contrastive focus that evokes alternatives to signal a contrast with a discourse referent. It's through its interaction with additional operators that FoCus can participate in a diverse range of more specialized contrastive interpretations, including exhaustive and mirative focus, or contrastive topic interpretations. Pretheoretically, we'll continue to use the standard, neutral, spellings for givenness and focus, and that includes occasions when we discuss examples or proposals from sources that do not necessarily assume the information structure notions we do.

Examples (1) to (2) below give a first illustration of Givenness and FoCus and their representation via $[\mathrm{G}]$-marking and $[\mathrm{FoC}]$-marking.

Me: Did anybody eat the clementines? I can't find them in the pantry.

You: (I think) Paula might [have eaten the clementines $]_{G}$.

Me: Sarah mailed the caramels.

You: (No), [Eliza $]_{\mathrm{FoC}}[\text { mailed the caramels }]_{\mathrm{G}}$.

Aunt: (Yes, and) $[\text { Ewan }]_{\mathrm{FoC}}[\text { mailed }]_{\mathrm{G}}[\text { the chocolates }]_{\mathrm{FoC}}$

In your answer in (1), the VP have eaten the clementines is Given. The concept of having eaten the clementines has just been mentioned. Its Givenness is reflected by the lack of prosodic prominence on eaten and clementines in Standard American and British English. The context of your answer in (1) discourages (but doesn't exclude completely) an interpretation where Paula is a FoCus. On its most natural interpretation, you aren't contrasting Paula with other people who might have eaten the clementines. Paula is merely new, then. Anticipating arguments still to come, Paula isn't marked with any feature in (1). In (2), the VP mailed the caramels in your reply is Given, too, but the subject Eliza is now a FoCus, not merely new. FoCus on Eliza evokes alternatives to Eliza: other people who might have mailed the caramels. Since Sarah is one of them and has just been mentioned, your reply represents a contrast with what I said. In her reply in (2), Aunt repeats the verb mailed and places FoCus on both Ewan and the chocolates. As a result, the set of FoCus alternatives determined by her utterance contains the two propositions expressed by you and me in the earlier parts of this discourse. Aunt's contribution to the conversation in (2) thus represents a contrast with both my utterance and your reply. The phonological and semantic/pragmatic properties of [G]-marking and [FoC]-marking will be discussed in detail in sections 7 and 8, so we will not go beyond this introductory illustration for now.

Features are the building blocks of natural language and are standard currency in phonology. Yet, unlike phonology, "syntax has no articulatory tract in which to ground its features" and, as a consequence, "the algorithms that build sentences are better researched than the atoms these algorithms operate over." ${ }^{3}$ Features related to information structure notions are well-established in cartographic approaches to syntax since Rizzi (1997), and are also assumed to influence the mapping from syntactic to prosodic structure in Bocci (2013). Yet they don't appear in Corbett's (2012) list of canonical morphosyntactic features, for example. Nor are they standard currency in contemporary theories of information structure. For many scholars the existence of morphosyntactic features for givenness

\footnotetext{
${ }^{2}$ We stopped short of using Vallduví \& Vilkuna's (1998) label Kontrast instead of FoCus so as to not prejudge the notion of contrast targeted here. For example, we are not committed to the view that wh-expressions are instances of FoCused expressions, as suggested by Vallduví \& Vilkuna, see also Beck (2006).

${ }^{3}$ British Academy conference announcement for the Alphabet of Universal Grammar: https://www.thebritishacademy.ac.uk/events/alphabet-universal-grammar.
} 
or focus is still very much in doubt. For example, Williams (1997: 610) concludes "that it would not be appropriate to supply syntax with a feature [+Focus] assigned to focused constituents, where that feature would have the obvious semantic, syntactic, and phonological interpretations." At the end of his paper on givenness, Schwarzschild notes that the $\mathrm{F}$ (ocus)-feature representations used throughout his paper "have no significant syntactic properties. From the point of view of the grammar overall, they are a nuisance and do not shed light on the real question of what semantic information is relevant to phonology and what parts of the phonology see this information. Ultimately, they should be done away with" (Schwarzschild 1999: 175). Zubizarreta \& Vergnaud (2006: 561) level a similar objection against the F(ocus)-feature of Selkirk (1984; 1995): "This feature is undesirable because it lacks independent justification. It is only needed to establish the relation between pitch accent and the informational structure of the sentence." Those authors all see a remedy in representations via metrical trees or metrically annotated syntactic trees, along with Ladd (1980; 1996; 2008), Reinhart (2006), Szendrői (2001; 2017a; 2017b), Wagner (2005; 2012), Calhoun (2010), Williams (2012), and Büring (2015b).

Metrical tree approaches to information structure can be traced back to Ladd (1980). On some implementations, the input for the computation calculating the discourse anaphoric impact of prosodic prominence in English are binary branching metrical trees, as in Liberman \& Prince (1977), or metrically annotated syntactic trees, as in Zubizarreta (1998), building on Halle \& Vergnaud (1987). Metrical trees or metrically annotated syntactic trees represent relative prominence relations between sister constituents. For English, it is claimed that the default is for a left-hand sister to be weak and for a righthand sister to be strong. Deviations from the default signal the impact of information structure. When a sister that should be weak by default is actually strong, we can infer that it is a focus, and when a sister that should be strong by default is actually weak, we know that it is given. On such an approach, the computation of discourse requirements attached to givenness and focus would track deviations from the default prominence pattern. ${ }^{4}$ A separate representation of givenness or focus via features might seem superfluous.

Metrical tree approaches to givenness and focus imply that in English, for example, the computation of meanings has access not only to the actual metrical trees associated with an expression, but also to information about English default prosody. While this architecture for the computation of meanings is technically possible, as demonstrated in Büring (2015b), it flies in the face of current views on grammatical architecture that assume that the meanings of complex expressions are compositionally projected from the meanings of lexical items and features and the way they are syntactically arranged. The question is then whether the mere fact that languages like Standard American and British English happen to rely on prosody to convey meanings related to givenness and focus forces us to abandon established assumptions about the computation of meaning in grammar.

\section{Syntactic evidence for features [FoC] and [G]}

In this section, we present a typological argument against metrical tree or metrically annotated syntactic tree representations of notions related to givenness and focus, or more generally, against any representation of those notions that does not rely on features. We will review examples from the literature that establish that, crosslinguistically, givenness and contrast-related notions of focus can trigger movement, agreement, or ellipsis, hence are responsible for syntactic behavior that has been taken to be diagnostic of the presence of features. Moreover, crosslinguistically, those features are not necessarily realized pro-

\footnotetext{
${ }^{4}$ Ladd (1996; 2008) makes clear that, ultimately, richer prosodic representations including information about prosodic phrasing would be needed.
} 
sodically. Featureless metrical trees or metrically annotated syntactic trees don't look like the right cure for the problems with F(ocus)-feature representations like those of Selkirk (1984; 1995), then. A syntactically unmotivated feature representation would be replaced by a grammatical architecture that doesn't generalize beyond languages like English and its kin. We need to find a different cure.

Cartographic studies since Rizzi (1997) have accumulated a rich body of evidence documenting that features related to information structure can drive movement to the left periphery. Aboh (2007a; 2007b; 2010; 2016) documents that the Gbe language Gungbe (spoken in Benin) uses overt particles to mark topics and (a contrast-related type of) focus. The particles appear in left-peripheral positions and attract topical or focused constituents to the edge of their projections. 3(a) and (b) illustrate constructions with the focus particle $w \grave{\varepsilon} .{ }^{5}$

Gungbe (Aboh 2007a: 289)
a. Sćsínú wè dà Àsíàbá.
Sessinou FOC marry Asiaba
'SESSINOU married Asiaba.'
b. Àsíàbá wè Sésínú dà.
Asiaba FOC Sessinou marry
'Sessinou married ASIABA.'

According to Aboh (personal communication), neither he nor other native speakers who have worked on those constructions perceive any prosodic difference between neutral and focused constituents, but he cautions that there hasn't yet been any systematic research on this. Fiedler \& Jannedy's (2013) phonetic study of focus constructions in the related Gbe language Ewe concludes that there is no primary prosodic focus marking in Ewe. More specifically, they did not find evidence for any prosodic properties of ex situ (displaced) focus phrases that could not be attributed to general prosodic effects of phrasing and the lexical high tone of the focus marking particle.

Like Gungbe, Wolof, an Atlantic language spoken in Senegal and the Gambia, has a left-peripheral position that can serve as the landing site for (contrastively) focused constituents (Torrence 2013). ${ }^{6}$

Wolof (Torrence 2013: 182)
a. Xale bi 1-a-a gis.
child the XPL-COP-1SG see
'It's the child that I saw.'
b. Ca lekkool ba 1-a-a gis-e Isaa. $P$ school the XPL-COP-1SG see-APPL Isaa 'It's at school that I saw Isaa.'
c. Gaaw 1-a-a ubbe-e bunt bi. quickly XPL-COP-1SG open-MANN door the 'It's quickly that I opened the door.'

Torrence (2013) analyzes 4(a) to (c) as cleft constructions that are the result of movement of the clefted constituent into the left periphery. Martinovič (2015) maintains that constructions like those illustrated in 4(a) to (c) are not clefts, but genuinely monocausal.

\footnotetext{
${ }^{5}$ Glosses: $F O C$ for focus particle. Here and in all following examples, glosses and translations are exactly as given in the cited source, except for style and capitalization.

${ }^{6}$ Glosses: $1 S G$ for first person singular, APPL for applicative, COP for copula, MANN for manner suffix, XPL for expletive. $P$ seems to stand for preposition.
} 
On either account, Wolof has movement into the left periphery that is triggered by focus. Most importantly for our argument, acoustic studies have shown that there are no prosodic reflexes of focus in Wolof. Rialland \& Robert (2001) conducted acoustic analyses of several natural and elicited Wolof corpora and found that Wolof has no prosodic marking of focus: "The originality of Wolof is that it has no prosodic marking of focus, even optionally" (Rialland \& Robert 2001: 937). There is essentially level pitch in all sentence types, except at the edges of intonational phrases, where tonal morphemes independent of information structure appear.

The fact that contrast-related notions of focus are not necessarily realized prosodically speaks against an architecture where their meaning contributions are represented by metrical trees. That the manifestation of those notions may trigger displacement into the left periphery in some languages looks like evidence for the presence of a syntactic feature. The general relevance of contrast, as opposed to mere newness, for movement into the left periphery is emphasized in Molnár \& Winkler (2010), building on earlier work documenting the linguistic importance of contrast, including Vallduví \& Vilkuna (1998) and Molnár (2006).

When relying on crosslinguistic facts as evidence for the existence of a feature like our [FoC], we need to contend with a concern voiced in Horvath (2010). Horvath points out that, in Hungarian, a merely contrastive interpretation is not sufficient for a constituent to appear in the left periphery. What's required is an exhaustive interpretation, excluding all but the mentioned alternative (Szabolcsi 1981). More generally, looking at constructions where focused constituents appear in the left periphery, we typically find subtly different interpretations. Apart from exhaustive interpretations, we may see contrastive topic or mirative interpretations, for example.

In current semantic work on association with focus, exhaustive, contrastive topic, or mirative interpretations are compositionally derived through the interaction of focused constituents with particular focus-sensitive operators, which might be silent, but could also be spelled out tonally or segmentally (Constant 2012; 2014; Bianchi et al. 2016; Fox \& Spector 2018; Bade \& Sachs 2019). For example, contrastive topics in English trigger a requirement for a discourse antecedent corresponding to a complex, sorted, question (Büring 2003). Constant $(2012 ;$ 2014) showed that this discourse requirement can be computed compositionally from a syntactic configuration where a left-peripheral contrastive topic operator attracts a focused phrase from a sister constituent that has another focused phrase in it. On such an approach, a contrastive topic phrase and an exhaustive focus phrase, for example, both carry a focus feature. What distinguishes the two is their association with different focus attracting operators: a covert exhaustivity operator for exhaustive focus, and a covert contrastive topic operator for contrastive topics. In line with cartographic work (Rizzi 1997), those operators might very well occupy distinct left-peripheral positions, thus providing distinct landing sites. Assuming compositional accounts along those lines, our $[\mathrm{FoC}]$-feature could be at the core of a whole range of subtly different interpretations, all involving FoCus in one way or other. In each case, an operator that evaluates FoCus alternatives attracts a [FoC]-marked phrase that provides those alternatives. It seems, then, that we are justified in taking the crosslinguistic facts featured in this section as evidence for the presence of a [FoC]-feature, even though the observed interpretations might be subtly different from each other. By way of illustration, we will spell out the technical details of how our [FoC]-feature associates with an exhaustivity operator in section $8 .^{7}$

\footnotetext{
${ }^{7}$ The relevant definitions and examples are (55) to (57) in section 8 below. We chose overt only as our illustration of an exhaustivity operator there, but a Hungarian-style covert exhaustivity operator would follow
} 
A contrast-related notion of focus can also trigger overt agreement in some languages. In the 'focus concord' constructions of Sinhala, Pre-Modern Japanese, and the Ryukyuan languages (Aldridge 2018; Kishimoto 2018; Slade 2018; Whitman 1997), (contrastively) focused phrases are marked with a particle that covaries with special inflection on the predicate. (5) is an example from Sinhala, an Indo-Iranian language spoken in Sri Lanka. ${ }^{8}$

Sinhala (Kishimoto 2018: 2)

a. Ranjit [Chitra ee potə tamay kieuw-e kiyəla] dannəw-a. Ranjit Chitra that book FOC read-E that know-A 'Ranjit knows that it was that book that Chitra read.'

b. Ranjit [Chitra ee potə tamay kieuw-a kiyəla] dann-e. Ranjit Chitra that book FOC read-A that know-E 'It is that book that Ranjit knows that Chitra read.'

In 5(a) and (b), the particle tamay marks ee pota ('that book') as a focus. The scope of the focus is indicated by the $-e$ ending of the verb, which has to appear here instead of the default $-a$ ending. In 5(a), the scope of the focus is just the embedded sentence. 5(a) conveys that Ranjit knows that what Chitra read was that book (and not anything else). In 5(b), on the other hand, the scope of the focus is the whole sentence. 5(b) conveys that what Ranjit knows Chitra read is that book (and not anything else). 5(b), but not 5(a) should thus be compatible with a situation where, unbeknownst to Ranjit, Chitra also read a magazine.

Hagstrom $(1998 ; 2004)$ and Kishimoto (2018) suggest that there is feature agreement between the focus particle tamay and the scope site of focus marked by the $e$-form of the verb in examples like 5(a) or (b). Both authors argue (in different ways) that the nature of this relation forces the focus particle to move to its scope site overtly or covertly. ${ }^{9}(6)$ would be the result of an overt instance of this movement.

Sinhala (Kishimoto 2018: 3 )
[Ranjit ee potə kieuw-a] tamay
Ranjit that book read-A FOC
'It was only that Ranjit read that book.'

In (6), tamay appears clause finally and with the $a$-form of the verb. In this position, tamay doesn't delimit the focused constituent, as in 5(a) and (b), but marks the scope site of the focus. (6) has several interpretations depending on which part of the scope of tamay is understood as focused. It may convey that it was Ranjit who read that book, that it was that book that Ranjit read, that Ranjit did read that book, and so on.

A feature agreement relation between particles that mark (contrastively) focused constituents and inflection on a nearby predicate has also been posited for the kakari-musubi construction found in Premodern Japanese and in the Ryukyuan languages (Whitman 1997; Aldridge 2018). ${ }^{10}$

the same model. Constant $(2012 ; 2014)$ and Bianchi et al. (2016) provide the technical details of how to derive contrastive topic and mirative interpretations along the lines we have outlined above.

${ }^{8}$ Glosses: $A$ for $-a$ inflection, $E$ for $-e$ inflection, $F O C$ for focus.

${ }^{9}$ For Hagstrom, the $-e$ form of the verb has an uninterpretable focus feature that needs to be checked. For Kishimoto, the movement of the focus particle is criterial in the sense of Rizzi (1997): the particle moves into a dedicated focus position in the CP layer of the sentence.

${ }^{10}$ Glosses: $N E G$ for negation, $I Z$ for izen 'realis' inflection, TOP for topic, $M O D$ for modal, $R T$ for rentai 'adnominal' inflection. 


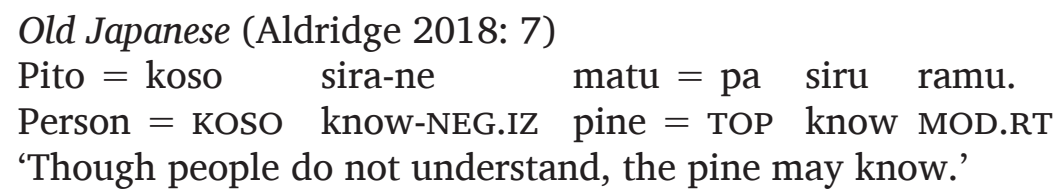

In (7), the contrastive focus particle koso triggers the izen 'realis' inflection on the predicate, which would not be used here in the absence of koso. This dependence between a focus particle and inflection on the predicate has been analyzed as feature agreement by several researchers, including Ikawa (1998), Kuroda (2007), and Aldridge (2018).

Taken together, the data we have reviewed so far warrant the conclusion that there are languages that represent contrast-related notions of focus with features that are visible to syntactic operations like displacement and agreement. Most importantly for our argument here, among those languages are some where contrast-related notions of focus are not realized prosodically. This precludes grammatical architectures that directly link discourse effects related to givenness and focus to representations of prosody or to metrically interpreted syntactic trees.

Turning to potential syntactic effects of givenness, Šimík and Wierzba (2015) argue (against Kučerová 2012) that Givenness (in the sense intended here), rather than presuppositionality, is reflected in Czech word order variation. According to Šimík and Wierzba, Czech Given phrases avoid stress, but, unlike English Given phrases, they move to left-peripheral positions to escape the canonical, rightmost, sentence stress position in Czech. Šimík and Wierzba's work establishes a bridge to the work of Reinhart (2006) and Szendrói (2001; 2017a; 2017b), pointing to the possibility that the [G]-feature, and possibly also the [FoC]-feature in some languages, might drive movement that aims at creating an output that conforms to general prosodic constraints for a language.

Givenness also seems to play a crucial role in VP-Preposing in English, as analyzed in Samko (2016), ${ }^{11}$ and in licensing ellipsis, as observed in Tancredi (1992), Rooth (1992b), and Winkler (2016). A syntactic feature related to Givenness, e-Givenness, was posited in Merchant (2001) to license ellipsis under certain conditions, some of which are syntactic, and some are semantic in nature. The e-Givenness feature requires a strong version of Givenness for its sister constituent, licenses non-pronunciation of that constituent at the syntax-phonology interface, and has a distribution that depends on syntactic properties of the phrase structure trees it occurs in. Merchant's e-Givenness feature thus has the kind of properties that we expect $[\mathrm{G}]$ and $[\mathrm{FoC}]$ to have, too. ${ }^{12}$

This section has presented crosslinguistic evidence for the existence of syntactically well-motivated features related to Givenness and FoCus. Our next move is now to bring out the disconnect between syntactically well-motivated morphosyntactic features like $[\mathrm{FoC}]$ and $[\mathrm{G}]$ and the widely assumed more general $\mathrm{F}$ (ocus)-marking systems originating with Selkirk (1984; 1995) and standardly assumed in semantic work. The following section will present the essentials of the F(ocus)-marking systems of Rooth (1992a) and Schwarzschild (1999), and thereby steer the discussion towards a theoretical dilemma: a feature system that has rightly been accused of lacking independent morphosyntactic motivation comes with what looks like unrivalled theoretical elegance in delivering a unified account of the discourse anaphoric effects of givenness and focus. Once the dilemma is identified, we can begin to look for ways to overcome it.

\footnotetext{
${ }^{11}$ We thank Jim McCloskey for alerting us to Samko's work.

${ }^{12}$ See Merchant (2019) for an overview of various analytic options.
} 


\section{Just $\mathrm{F}$ (ocus)-marking?}

In this section, we'll present the leading ideas common to Rooth and Schwarzschild in a unified system. We will use Rooth's Alternatives Semantics (Rooth 1992a) to state Schwarzschild's (1999) discourse anaphoric requirements for Givenness and FoCus, following the presentation in Rooth (2015). ${ }^{13}$ A fundamental assumption of Rooth (1985; 1992a) and Schwarzschild (1999), which is inherited from Selkirk (1984; 1995), is that there is a single [F]-feature that uniformly marks constituents that are FoCused (in our sense) and those that are merely new (hence not Given in our sense). Given constituents remain unmarked. This is illustrated in (8) and (9) below.

(8) Me: Did anybody eat the clementines? I can't find them in the pantry.

You: (I think) [Paula $]_{\mathrm{F}}$ might have eaten the clementines.

(9) Me: Sarah mailed the caramels.

You: (No), $[\text { Eliza }]_{\mathrm{F}}$ mailed the caramels.

Historically, one motivation that has led to such uniform [F]-marking accounts - and the very notion of 'information focus' - is that in Standard American and British English, pitch accents are associated with material that could be FoCused or merely discourse new. The distribution of pitch accents thus seems to indicate that English prosody treats FoCused and merely discourse new phrases the same.

If discourse new constituents are consistently [F]-marked, representations of all new, outof-the-blue, utterances wind up with a nested [F]-marking structure, as illustrated in (10):

$$
\left[\text { Sarah }_{\mathrm{F}}\left[\text { mailed }_{\mathrm{F}} \text { the caramels }\right]_{\mathrm{F}}\right]_{\mathrm{F}} \text {. }
$$

(10) is peppered with [F]-marks. It's representations like (10) that most vividly bring out the disconnect with bona fide morphosyntactic features that could also play a role in syntactic operations like displacement or agreement.

Yet Rooth and Schwarzschild have proposed accounts that are capable of computing the apparently distinct discourse requirements imposed by FoCus and Givenness from representations that only have [F]-marking. By way of illustration, look again at your answer in (9), repeated here as (11):

$$
[\text { Eliza }]_{\mathrm{F}} \text { mailed the caramels. }
$$

(11) is not acceptable as an out-of-the-blue utterance. The VP mailed the caramels needs to be Given in our sense, and the sentence as a whole might also express a contrast, possibly with something that was said earlier. Schwarzschild (1999) proposes a unified characterization of those two discourse anaphoric relations in terms of a generalized notion of givenness that subsumes both our Givenness and FoCus. Schwarzschild requires that any constituent that is not [F]-marked be given in this generalized sense. In (11), neither the VP or its parts, nor the sentence as a whole are [F]-marked, hence those constituents all need to come out as given on his approach.

The Alternatives Semantics of Rooth provides a convenient characterization of Schwarzschild's generalized notion of givenness, referred to as A-Givenness from now on. ${ }^{14}$ We can say that a constituent $\alpha$ is A-Given (in a context) just in case there is a

\footnotetext{
${ }^{13}$ This section also serves as an introduction to Rooth's Alternatives Semantics, which our own proposals in section 8 will be couched in, too.

${ }^{14}$ Schwarzschild states his generalized notion of givenness in terms of generalized entailment. As Rooth (2016) points out, Schwarzschild's generalized entailment condition for givenness is sometimes too easy to satisfy. Take (i):
} 
salient discourse referent (an individual, concept, or proposition) that is a member of the alternatives set associated with $\alpha$. In Alternatives Semantics, every expression is assigned two semantic values: its O(rdinary)-value, and its A(lternatives)-value, which is its alternatives set. For example, the O-value of (11) is just the proposition that Eliza mailed the caramels. Its A-value is the set of propositions in (12).

\{'Eliza mailed the caramels', 'Sarah mailed the caramels', 'Leif mailed the caramels', ...\}.

Since the proposition that Sarah mailed the caramels is in the alternatives set (12) for (11) and, in the context of (9), has just been mentioned, (11) as a whole satisfies Schwarzschild's A-Givenness requirement in that context.

To compute the alternatives set for (11) compositionally, we combine the A-values of its immediate constituents, the $[\mathrm{F}]$-marked subject $[\text { Eliza }]_{F}$ and the VP mailed the caramels. The A-value of [Eliza $]_{F}$ is the set of all individuals - Eliza, Sarah, Leif, and anybody else in our domain of discourse. What about the A-value of the VP mailed the caramels, which contains no [F]-marks? In Rooth's Alternatives Semantics, that VP's A-value is a singleton set, the set containing the VP's O-value as its only member. That's the singleton set containing the property of having mailed the caramels. The A-value of (11) as a whole is computed by pointwise combination of the A-values of $[\text { Eliza }]_{F}$ and the VP mailed the caramels: \{Eliza, Sarah, Leif, ... $\times \times$ 'mailed the caramels' $\}$. The result is the alternatives set (12).

Our Givenness falls out as a special case of A-Givenness. Since the VP mailed the caramels in (11) has a singleton alternatives set, it is A-Given just in case its only member, the property of having mailed the caramels, is salient in the discourse context, hence is Given in our sense. That, too, is the case in the context of (9).

Rooth's and Schwarzschild's systems provide unified accounts of the discourse requirements triggered by FoCus and Givenness. It looks like there really aren't TWO such discourse requirements. Givenness and FoCus come out as two sides of the same coin. Rooth's and Schwarzschild's systems only require a single focus-related feature: [F]-marking. Neither FoCus nor Givenness need to be represented separately. The case for a unified account of Givenness and FoCus in terms of [F]-marking is strong indeed. Given the theoretical elegance and unifying power of $[\mathrm{F}]$-marking systems, should we still worry about the disconnect with syntactically motivated features?

We should. The following section will collect together empirical problems for uniform [F]-marking approaches. We will present data telling us in no uncertain terms that grammar makes a distinction between FoCus and discourse newness. The two notions shouldn't be represented by a single feature.

\section{Newness and FoCus can't be lumped together}

Since at least Chafe (1976), syntacticians, phonologists, and phoneticians, have documented differences between different types of focus in a number of languages. Many of those authors have pointed to differences in the way languages mark constituents that are merely discourse new (newness focus, information focus), as opposed to constituents that

(i) Every $[\text { cat }]_{\mathrm{F}}$ is a complainer.

For Schwarzschild, (i) as a whole is given just in case (ii) is entailed by prior context:

(ii) $\quad \exists \mathrm{P}$ [every $\mathrm{P}$ is a complainer].

But there is always the property of being a complainer, hence (ii) is trivially true, since every complainer is a complainer. Every context thus entails (ii). Defining the relevant notion of givenness within Alternatives Semantics does not run into this problem. 
evoke alternatives and thereby signal a contrast (FoCus). ${ }^{15}$ In this section, we will discuss some representative examples. We will conclude that those examples pose challenges for representations of the semantic/pragmatic and phonological effects of FoCus and Givenness that rely on [F]-marking alone.

Our first example comes from Katz \& Selkirk's experimental materials (Katz \& Selkirk 2011, 802).

(13) Gary is an art dealer. Lately he's been very picky about which museum he deals with; he doesn't do business with the Metropolitan or the Guggenheim. So he would only offer that Modigliani to MoMA. He says that's the only museum with a space good enough to hang it in.

Our target sentence within (13) is (14). ${ }^{16}$

He would ónly offer that Modigliáni to MóMA.

Both Modigliani and MoMA in (14) bear obligatory pitch accents when read aloud in the context of (13). But there are important differences between the two. In the context of (13), MoMA introduces alternatives and thereby sets up a contrast with the Metropolitan and the Guggenheim, the other two museums mentioned. MoMA is a FoCus, then. Modigliani, on the other hand, presents merely new information. It doesn't evoke alternatives. In the context of (13), (14) implies that Gary wouldn't offer that Modigliani to the Metropolitan or the Guggenheim. Modigliani thus doesn't associate with only. It doesn't contribute any alternatives to the computation of the alternatives set that only operates over. That set is illustrated in (15).

\{'He would offer that Modigliani to MoMA', 'he would offer that Modigliani to the Metropolitan', 'he would offer that Modigliani to the Guggenheim', ...\}

Sentence (14) is true just in case the mentioned alternative 'He would offer that Modigliani to MoMA' is the only alternative in (15) that is true.

The scenario described in (13) also excludes the possibility that Modigliani in our target sentence might be a contrastive topic scoping over only. In the context of (13), (14) can't be understood as contrasting the mentioned Modigliani painting, which Gary would only offer to MoMA, with other paintings of his that he might also offer to the Metropolitan or the Guggenheim. Such an interpretation would go against what we are being told in the story, namely that Gary doesn't do business with the Metropolitan or the Guggenheim.

Finally, interpreting the merely new direct object outside the scope of only wouldn't be an option in (16) (still understood as a continuation of (13)), where the object contains a negative polarity item that is licensed by only, hence is trapped within the scope of only.

$$
\text { He would only offer that Modigliáni or any of his Móndrians to MóMA. }
$$

Katz \& Selkirk's examples show that the grammar of standard American English distinguishes constituents that are FoCused from those that are merely new. The difference

\footnotetext{
${ }^{15}$ Apart from Chafe (1976), these authors include Rochemont (1986; 2013a; 2013b), Pierrehumbert \& Beckman (1988), D’Imperio (1997), É. Kiss (1998), Vallduví \& Vilkuna (1998), Zubizarreta (1998), Gundel (1999), Frota (2000), Belletti (2001; 2004), Selkirk (2002; 2008), Gundel \& Fretheim (2004), Féry \& Samek-Lodovici (2006), Aboh (2007a; 2007b), Ameka (2010), Beaver \& Velleman (2011), Katz \& Selkirk (2011), Vallduví (2016), among many others.

${ }^{16}$ We use acute accents to indicate the location of pitch accents. Boldface for MóMa in (14) indicates greater phonetic prominence.
} 
can be detected in interactions with FoCus-sensitive operators like only. Katz \& Selkirk's paper isn't about the semantic effects of alternatives focus (FoCus) vs. information focus, though. Katz \& Selkirk (2011) is a phonetic study. They show that there is a systematic phonetic difference between FoCused and merely new material which, crucially, is independent of syntactic position. We'll come back to this aspect of their study in section 7 .

Within current [F]-marking-only approaches, both Modigliani and MoMA in our target sentence (14) (as part of (13)) would have to be [F]-marked, since both have a pitch accent. But then we would have no syntactic representation from which to compute the right alternatives set for only on the one hand, and the right prosody for Modigliani and MoMA on the other. ${ }^{17}$

English it-cleft constructions create a similar dilemma for [F]-marking-only approaches. It-clefts consist of a clefted constituent followed by the cleft clause (the subordinate clause), as in your reply in (17):

Me: Jane's lost her keys and is really upset.

You: It was her phone that Jane lost.

In it-cleft sentences the clefted constituent is a FoCus. In (17), Jane's phone is contrasted with her keys. In (17), it so happens that the material in the cleft clause is Given and lacks pitch accent(s). But as Prince (1978) observed, and Hedberg (1990; 2010; 2013) discussed, the material in the cleft clause may also be new, hence accented. (18) is one of the examples quoted by Prince (her example 39(b)). ${ }^{18}$

(18) The leaders of the militant homophile movement in America generally have been young people. It was they who fought back during a violent police raid on a Greenwich Village bar in 1969, an incident from which many gays date the birth of the modern crusade for homosexual rights.

Our target sentence within (18) is 19(a), and the cleft clause is 19(b).

a. It was théy who fought báck during a víolent políce raid on a Gréenwich Village bár in '1969.

b. ... who fought báck during a víolent políce raid on a Gréenwich Village bár in '1969.

The pronoun they in 19(a) is a FoCus. It singles out young people among other groups of people who could have fought back during that raid on a Greenwich Village bar. What's being said about young people in 19(b) is all new information, and that's reflected in the distribution of accents. To compute the inference that no other relevant group (apart from the young people) fought back during that violent police raid on a Greenwich Village bar in 1969 , we want to generate an alternatives set like that in (20).

\{The young people fought back during a violent police raid on a Greenwich Village bar in 1969, the older people fought back during a violent police raid on a Greenwich Village bar in $1969, \ldots\}$

But how are we going to generate this set if everything in the cleft clause 19(b) is new information, hence would have to be [F]-marked to account for the distribution of pitch accents? The dilemma for an [F]-marking-only approach is that the mechanism comput-

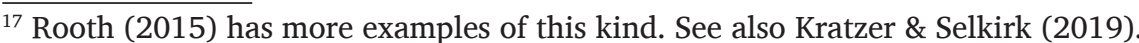

${ }^{18}$ The example is originally from the Pennsylvania Gazette, February 1977: 16.
} 
ing the set of FoCus alternatives wouldn't want to have any [F]-marks in the cleft clause, while the mechanism computing the prosody would need them. On an [F]-marking-only approach we would again have no syntactic representation from which to compute the right alternatives set on the one hand, and the right prosody on the other.

Our last example in this section illustrates an alternation in answers to constituent questions that has been reported for several languages, including Italian (É. Kiss 1998; Belletti 2001), Hungarian (É. Kiss 1998), Spanish (Zubizarreta 1998), Finnish (Molnár 2001), Gungbe (Aboh 2007a; 2007b), and Kwa languages more generally (Ameka 2010). For illustration, we will look at an Italian example. In Italian, a simple constituent question like 21(a) can be answered as in 21(b) or 21(c).

$$
\begin{aligned}
& \text { Italian } \\
& \text { a. Chi ha scritto questo articolo? } \\
& \text { who has written this article } \\
& \text { 'Who wrote this article?' } \\
& \text { b. L' ha scritto Gennaro. } \\
& \text { it has written Gennaro } \\
& \text { 'Gennaro wrote it.' } \\
& \text { c. Gennaro l'ha scritto. } \\
& \text { Gennaro it has written. } \\
& \text { 'Gennaro wrote it.' }
\end{aligned}
$$

As discussed by É. Kiss and Belletti, a question like 21(a) can be answered with a postverbal subject, as in 21(b), or a preverbal subject, as in 21(c). As an answer to 21(a), 21(c) necessarily expresses a contrast. Gennaro must be a FoCus, it can't be merely new. In 21(b), Gennaro could also be a FoCus, but doesn't have to be. ${ }^{19}$ It could also be merely new. Placing a FoCus on Gennaro would be natural in contexts where the possibility that others might have written this article is already in the air or could be evoked with such a FoCus. In the latter case, the information that Gennaro is the author of the article would be framed against the background of the possibility that others, one of the 'non-Gennaros', whoever they may be, might have written the article. We could think of this as an accommodated FoCus: it doesn't require an explicit discourse antecedent.

To bring out intuitions about preverbal vs. postverbal subjects in Italian more clearly, consider 22(a) and (b) below, still understood as answers to the question in 21(a). We made the answers longer, adding new information that was not explicitly asked for. This change seems to make it harder (not completely impossible) to accommodate a contrastive interpretation for the subject Gennaro. 22(a) and (b) are not naturally understood as contrasting Gennaro with others who might have written this article while being in Graduate School. As a result, there is pressure for Gennaro to appear postverbally. 22(b) is judged infelicitous as an answer to 21 (a). ${ }^{20}$

\section{Italian}

a. Credo che l'abbia scritto Gennaro quando era in Graduate I think that it has-SUBJ written Gennaro when was in Graduate School.

School.

'I think Gennaro wrote it when he was in Graduate School.'

\footnotetext{
${ }^{19}$ There may still be a subtle meaning difference between an in situ FoCus and a left-peripheral FoCus in Italian (Bianchi 2013). This difference might be contributed by a silent left-peripheral operator that attracts the FoCused phrase it associates with, as suggested by Delfitto \& Fiorin (2015).

20 The Italian examples were provided by Ilaria Frana and have been confirmed by other speakers of Italian. Glosses: $S U B J$ for subjunctive.
} 


\section{b. \#Credo che Gennaro l'abbia scritto quando era in Graduate I think that Gennaro it has-SUBJ written when was in Graduate School. \\ School. \\ 'I think Gennaro wrote it when he was in Graduate School.'}

É. Kiss and Belletti argue, following Rizzi (1997), that the preverbal subjects in sentences like 21(c) and 22(b) occupy a left-peripheral position reached via movement. The postverbal position of the subject is either its original position (É. Kiss) or a low position in the verb's functional projection (Belletti).

What is it that prevents Gennaro in (22) from moving to a left-peripheral position? Is it because Gennaro is not contrastive, hence not a FoCus? Or could it be that it is FoCused, but movement of Gennaro to the left periphery would imply association with an operator that would result in an implausible interpretation? In answers to constituent questions, any silent left-peripheral operator would most plausibly be an exhaustivity operator. But we constructed the example so that the answers in (22) are understood to be exhaustive: we infer that Gennaro and only Gennaro wrote that article. If there was a silent leftperipheral exhaustivity operator that a FoCused instance of Gennaro could associate with, then, there should be no obstacle for Gennaro to appear preverbally, contrary to fact. We conclude that what prevents Gennaro from appearing preverbally in (22) is that it's not naturally understood as FoCused. Examples like those in (22) thus show that the syntax of Italian makes a distinction between constituents that are FoCused and those that are merely new.

Summarizing the results of this section, we conclude that an [F]-feature-only account isn't able to connect meaning, syntax, and prosody in the right way. The grammars of natural language distinguish FoCused phrases from those that are merely new. The two notions can't be lumped together into a single feature. Accepting this conclusion, it raises an important question about the status of newness. If newness and FoCus can't be lumped together into a single feature, is newness represented by a separate morphosyntactic feature or does it remain unmarked?

\section{No feature for newness}

The last section concluded that FoCus and newness cannot be lumped together into a single feature. The question before us in this section is the theoretical status of newness. Does the universal repertoire of morphosyntactic features include a separate feature marking new information? The available crosslinguistic data do not allow us to answer this question conclusively. The discussion of answers to questions in Italian in the last section brought out the empirical difficulty. We saw that Italian makes a difference between subjects that are merely new and those that are contrastive, but to bring out that difference in a convincing way, we couldn't use a simple question-answer test. We had to make some effort to construct an example that discouraged accommodation of a contrastive interpretation for the new part of the answer. Crosslinguistic research happens to mostly use answers to questions as tests for focus. Answers to constituent questions are still "the most widespread and most widely used test for focus" (van der Wal 2016: 265). But, as we have seen, the new part of an answer to a constituent question might be contrastive or merely new, hence a simple question-answer test won't distinguish the two. As a consequence, the available crosslinguistic record on whether there are languages that mark mere newness is inconclusive. ${ }^{21}$ Given the lack of crosslinguistic evidence, we will turn

\footnotetext{
${ }^{21}$ An example illustrating the empirical difficulty is the discussion of in situ vs. ex situ focus in Hausa and other Chadic languages: Green \& Jaggar (2003), Jaggar (2006), Hartmann \& Zimmermann (2007), Zimmermann (2011). Hartmann \& Zimmermann document that the new part of an answer to a constituent question can
} 
our attention to English for the remainder of this article. We will argue that the grammar of Standard American and British English marks Givenness and FoCus, but is blind to newness. Material that is merely new ('information focus') remains unmarked in English. From a theoretical perspective, there is no such thing as 'information focus' in English.

The consequences of the assumption that newness might be unmarked in a language are momentous and haven't been fully appreciated in the literature. We have seen that the part of an answer that corresponds to the wh-part of a constituent question can be merely new. But if mere newness is unmarked and thus doesn't correspond to any grammatically relevant kind of focus, we can no longer say things like the "classical pragmatic use of focus is to highlight the part of an answer that corresponds to the wh-part of a constituent question" (Krifka 2008: 250), nor that in "an answer to a constituent question, the element corresponding to the <wh >-phrase must be a focus" (Büring 2016: 12). Büring, Krifka, and much of the traditional and contemporary literature on focus take 'answer focus' to be an unquestioned subtype of focus. The rationale for classifying 'answer focus' as a type of focus along with contrastive focus (our FoCus) is the assessment that these foci "behave identically in all respects" (Büring 2016: 23). The data we saw in the previous section go against this assessment.

There are even more far-reaching consequences of positing a category like 'answer focus'. If just about anything we say can be understood as being part of an answer to an implicit question under discussion, as Roberts (1996; 2012) has argued, then just about anything new we say should be part of an 'answer focus', which should then be marked for focus. But then we would again uniformly mark FoCus and newness, which we should not, as the previous section has shown.

Finally, if there is evidence that newness is unmarked in the grammar of English, the problematic data discussed in section 4 could not be accounted for by simply adding a [G]-feature to an [F]-marking-only system like that presented in section 3. Nor could we have a two-feature-system like that of Beaver \& Velleman (2011), where a separate [N]-feature marks new (or, more accurately, unpredictable) material.

Our argument for the unmarked status of newness ('information focus') in Standard American and British English comes from the syntax-phonology interface. The difference between marking vs. not marking newness is brought out most dramatically in out-ofthe-blue utterances like (23), where everything is new information. Accounts where newness is marked would produce representations that look minimally as in 23(a) (with an [N]-feature used for illustration), whereas accounts where newness is unmarked posit representations like 23(b).

(23) Sárah mailed the cáramels.

(a) Sarah $_{\mathrm{N}}$ mailed $_{\mathrm{N}}$ the caramels ${ }_{\mathrm{N}}$.

(b) Sarah mailed the caramels.

[N]-marking every content word in 23(a) is necessary since newness of a constituent in no way implies that its parts are new as well. Representations with merely broad [N]marking like (24) for out-of-the-blue utterances would thus be inadequate.

appear in situ or ex situ in Hausa, and they conclude from this that "information focus" can be realized in both of those positions. Since they didn't' control for accommodated contrasts in the answers, we can't quite draw that conclusion, though. Interestingly, in a corpus study, Hartmann and Zimmermann found that almost $80 \%$ of all cases they identified as "information focus" were realized in situ, while more than $90 \%$ of all cases they identified as "selective, contrastive, or corrective focus" were realized ex situ. 


$$
\text { [Sarah mailed the caramels }]_{\mathrm{N}} \text {. }
$$

The difference between 23(a) and (b) is critical for figuring out the architecture of the syntax-phonology interface. With 23(a), the prosody of the sentence would have to be read off a representation that has several instances of [N]-marks. With 23(b), on the other hand, the right prosody would have to be determined on the basis of a representation that does not contain any information structure features at all. This means that if 23(b) is right, there has to be a default prosody for English, all new, out-of-the-blue utterances whose principles are independent of any impact of information structure. To defend representations like 23(b) against 23(a), then, we need to make a case that there is such a default prosody and show how it can be derived within an otherwise plausible general theory of prosodic phonology. If the demonstration succeeds, we would have to reject 23(a) on conceptual grounds: All [N]-marks in 23(a) would be entirely superfluous as far as prosody is concerned.

Accounts presupposing the existence of a default prosody for English that is independent of information structure have been proposed since the earliest studies of prosody within Generative Grammar (Chomsky \& Halle 1968; Bresnan 1971; Chomsky 1971; Jackendoff 1972). The recognition of a default prosody for English is also at the very center of approaches linking the discourse effects of givenness and focus to prosodic structures or metrically interpreted syntactic trees. ${ }^{22}$ While there have been dissenting opinions in the past (Bolinger 1965; Schmerling 1976), the existence of English default prosodic phonology is now generally acknowledged (Truckenbrodt 1995; 2006; 2007a; 2016; Gussenhoven 2004; Féry \& Samek-Lodovici 2006; Selkirk 2008; Büring 2016; Féry 2017). We therefore expect that representations like 23(a) for all-new sentences are not an option.

If there is no such thing as 'information focus' or 'newness focus' in Standard American and British English, and the apparent prosodic effects of newness are the result of default prosody, we can seriously consider the possibility that the effects of information structure on prosody in Standard American and British English can be traced back to the impact of the syntactically well-motivated features [FoC] and [G] and other equally well-motivated features like them. The cure for the disconnect between information structure features like the F(ocus)-feature of Selkirk $(1984 ; 1995)$ and syntactically motivated features would then not consist in abandoning feature representations for information structure altogether. What we would need to do is reconceptualize and reconfigure the repertoire of such features. Selkirk (1984; 1995), Rooth (1985; 1992a), Schwarzschild (1999), and Beaver \& Velleman (2011) went wrong by assuming that English represents newness. There is no feature for newness in English, nor is there a feature that lumps together FoCus and newness.

\section{Deriving the prosody of all-new declarative sentences}

In this section we will put a proposal on the table showing how prosodic representations of all new declarative sentences in Standard American and British English can be derived by default. Our account of the default prosody of Standard American and British English includes the representation of prosodic constituent structure, of prosodic prominence patterns, and of accent and edge tones. One part of the account specifies the relation between prosodic constituency and the morphosyntactic constituency of a sentence. The other

${ }^{22}$ See e.g. the overviews in Arregi (2016) and Zubizarreta (2016). 
shows how the phonology of Standard American and British English derives the distribution of tone and prosodic prominence as a function of prosodic constituency. While this is not the place to engage in detailed comparisons of competing accounts of default prosody, we will make sure that every part of our proposal is typologically well-motivated quite independently of information structure. In fact, there won't be, and there shouldn't be, any mention of any information structure notions in this section.

\subsection{Theoretical background}

The sentence types we will consider will be 'pragmatically neutral' in that they do not make use of any of the surface tones or tone combinations ('tunes') that are used in Standard American and British English to convey a variety of discourse-related meanings (Ladd 1980; 2008; Pierrehumbert 1980; Gussenhoven 1983; 2004; Pierrehumbert \& Hirschberg 1990; Bartels 1999; Truckenbrodt 2012b). The predictable pitch accents that appear with merely new constituents in Standard American and British English will be argued to be instances of meaningless epenthetic tones such as are commonly found crosslinguistically.

Our account assumes the three distinct levels of grammatical representation illustrated in 25 (a) to (c). ${ }^{23}$

(25) Sarah mailed the caramels

a. Morphosyntactic output representation (MSO):

$\left[\left[\text { Sarah }_{\mathrm{N}}\right]_{\mathrm{NP}}\left[[\text { mail-ed }]_{\mathrm{V}}\left[\text { the }\left[[\text { caramel-s }]_{\mathrm{N}}\right]_{\mathrm{NP}}\right]_{\mathrm{DP}}\right]_{\mathrm{VP}}\right]_{\text {Clause }}$

b. Phonological input representation (PI):

$((($ Sarah $) \omega) \varphi($ (mailed) $\omega$ (the ((caramels) $\omega) \varphi) \varphi) \varphi) \imath$

c. Phonological output representation (PO):

( ((Sár.ah) $\left.\omega^{\prime}\right) \varphi\left(((\right.$ máiled $) \omega$ the $) \omega\left((\right.$ cár.a.mèls $\left.\left.\left.) \omega^{\prime}\right) \varphi^{\prime}\right) \varphi\right) \imath$

$\begin{array}{lllll}\mathrm{H} & \mathrm{L} & \sim \mathrm{H} & \mathrm{H}\end{array}$

25(a) is the morphosyntactic output (MSO) representation of an all-new declarative sentence. 25(b) is the phonological input (PI) representation of the sentence; 25(c) is the phonological output (PO) representation, which is submitted to phonetic interpretation. The PO representation 25(c) includes the full array of prosodic properties of an all-new declarative sentence, better viewed in the formally equivalent tree in Figure 1.

The grammatical organization illustrated in (25) is schematized in (26).

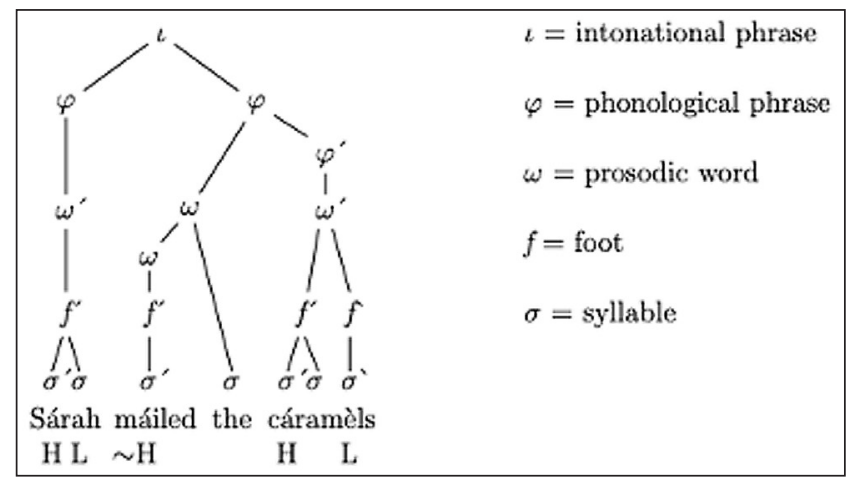

Figure 1: PO (25c) in tree version.

\footnotetext{
${ }^{23}$ Our displays of MSOs use familiar syntactic labels, even though for the mapping from MSO to PI, category differences between Words (e.g. N vs. v) or between Phrases (e.g. NP vs. VP) do not play a role.
} 
Morpho-Syntactic Output Representation (MSO)

$\downarrow$ Spellout (gives phonological expression to MSO)

Phonological Input Representation (PI)

$\downarrow$ Phonology (determines optimal PO on basis of PI)

Phonological Output Representation (PO)

Phonetic Interpretation

A few remarks on the notation in (25) and Figure 1: The non-italic orthographic representations of the words in PO (and PI) are a convenient substitute for the phonological feature representations of their segmental content. The notations $\mathrm{H}$ and L stand for high and low tones. (The $\sim$ indicates the optional status of a following H.) The orthographic acute and grave accent marks on the vowels indicate the head or prominent ('stressed') status of the syllables containing them: orthographic acute accent for the syllable that has the head prominence ('main stress') of the prosodic word $\omega$, grave accent for the syllable with merely foot-head prominence. A superscript acute accent on a prosodic $\omega$ or phonological phrase $\varphi$ indicates its head-prominence status at the next higher level of prosodic constituency.

Regarding the grammatical model we are assuming, we'd like to emphasize that this kind of architecture is not an unfamiliar one. Most properties of the three successive representations are widely assumed. Consider first the output phonological representation (PO), which is submitted to phonetic interpretation. Notably, its prosodic constituent organization, the prosodic prominence patterns and the tones (illustrated in 25(c) and Figure 1) have to be there since they may all contribute to the quantitative phonetic interpretation of the sentence (Shattuck-Hufnagel \& Turk 1996; Keating et al. 2004).

A fundamental property of the phonological output representation PO (illustrated in 25(c)) is that it includes a linear organization of the words of the sentence. This linearization is largely inherited from the phonological input PI (illustrated by 25(b)). A linearized PI for the sentence as a whole, as in 25(b), is presupposed in any work which treats phonological phenomena that apply between successive words of a sentence. These phenomena include inter-word vowel coalescence, segmental feature assimilation or lexical tone spread, for example. In cases of inter-word phonological phenomena there are phonological constraint-induced changes between the distribution of segmental and tonal phonological features in the PI and their distribution in the PO of the sentence (see e.g. Nespor \& Vogel 1986, Truckenbrodt 1999, and the articles in Selkirk \& Lee 2015). The contribution of the morphosyntactic output representation (MSO) to the linearization of PI is the topic of active research, and so are possible phonologically induced changes in linear order. In the model of grammar we are entertaining, phonological effects on linearization might be understandable as part of spellout (the mapping from MSO to PI) or as part of the phonology per se (the mapping from PI to PO). ${ }^{24}$

The grammatical architecture displayed in (26) is compatible with Kiparsky's (2000) proposal that word phonology is characterized in terms of an optimality theoretic constraintbased input-output phonology for words, and that the output of the word phonology in

\footnotetext{
${ }^{24}$ Recent work has shown a broad range of phonological factors to be involved in characterizing attested variation in the order of words (see e.g. the papers in Gribanova \& Shih 2016). Of special interest to our concerns here are the demonstrations by Agbayani \& Golston (2010; 2016), Bennett, Elfner \& McCloskey (2016), and Kusmer (2019) that certain word orders observed in the phonological output representation involve movements of constituents defined in prosodic structure terms from and/or into positions that must be defined in terms of prosodic structure. Such cases would have a place in the Phonology module in (26), which relates a prosodically structured phonological input representation PI to its phonological output representation $\mathrm{PO}$, as illustrated above in (25)/Figure 1.
} 
turn provides the input for an OT constraint-based input-output phonology for sentences. We could assume that output representations of the word phonology form part of the MSO representation (25a) that maps onto the PI in (illustrated in 25(b)). Our writing with italics of the component words of the MSO is meant to indicate that we remain agnostic as to the precise phonological status of these words in MSO, an issue not central to our concerns. The architecture displayed in (26) is also compatible with a Distributed Morphology theory of post-syntactic morphological operations (see e.g. Halle \& Marantz 1993; 1994; Embick \& Noyer 2007). Our choice of the term 'MSO' ('morphosyntactic output') reflects this possible connection.

Since the phrasal head prominence ('stress') and tone of all-new pragmatically neutral declarative sentences are phonologically predictable in Standard American and British English, they are only introduced in the PO, as language-particular consequences of phonological markedness constraints relating prosodic constituent structure to prosodic head prominence and, directly or indirectly, to tone. The demonstration that the surface (output) phrasal tone and prominence in all new pragmatically neutral declarative sentences is phonologically predictable is our main argument that no morphosyntactic feature for newness is required in the grammar. ${ }^{25}$

\subsection{Deriving the prosodic constituent structure of a sentence}

Recall our illustration of the proposed derivation of the prosody of all-new utterances in American and British English, which is reproduced here:

(25) Sarah mailed the caramels

a. Morphosyntactic output representation (MSO):

$\left[\left[\text { Sarah }_{\mathrm{N}}\right]_{\mathrm{NP}}\left[[\text { mail-ed }]_{\mathrm{V}}\left[\text { the }\left[[\text { caramel-s }]_{\mathrm{N}}\right]_{\mathrm{NP}}\right]_{\mathrm{DP}}\right]_{\mathrm{VP}}\right]_{\text {Clause }}$

b. Phonological input representation (PI):

$((($ Sarah $) \omega) \varphi($ (mailed) $\omega$ (the ((caramels) $\omega) \varphi) \varphi) \varphi) \imath$

c. Phonological output representation (PO):

$\left(\left((\right.\right.$ Sár.ah $\left.) \omega^{\prime}\right) \varphi\left(((\right.$ máiled $) \omega$ the $) \omega\left((\right.$ cár.a.mèls $\left.\left.\left.) \omega^{\prime}\right) \varphi^{\prime}\right) \varphi\right) \imath$

$\begin{array}{llll}\mathrm{H} \mathrm{L} & \sim \mathrm{H} & \mathrm{H} & \mathrm{L}\end{array}$

In line with Match Theory (Selkirk 2009; 2011; Elfner 2012; 2015) we assume that the morphosyntactic Words of the MSO representation 25(a) correspond to prosodic words, labeled $\omega$, in the PI representation 25(b), the syntactic Phrases correspond to phonological phrases, labeled $\varphi$, and the Clause or Root node corresponds to an intonational phrase, labelled ı. The type of morphosyntactic constituent we are calling a "Word" consists of a lexical root and whatever lexical or functional heads might be adjoined to it, through head movement or morphological operations. ${ }^{26}$ What we are calling a "Phrase" minimally dominates a Word and possibly another Phrase. ${ }^{27}$

(27) below states our first constraint on phonological spellout, MatchWord. ${ }^{28}$ MatchWord says that every instance of a Word in MSO corresponds to exactly one instance of a prosodic word in PI.

\footnotetext{
${ }^{25}$ At the same time this demonstration will show that there is also no motivation for a focus morpheme with lexical H tone contra Selkirk (1984).

${ }^{26}$ Inclusion of (certain) functional heads within a Word has the consequence of eliminating the related functional projections in MSO. It's for this reason that the phrase structure of the MSO 25(a) looks so simple - the only overt functional head that heads a Phrase is the determiner the.

${ }^{27}$ Research on what counts as a Clause, a Phrase, or a Word in spelling out MSO is ongoing. See e.g. Selkirk (2009; 2011), Ito \& Mester (2012; 2013), the articles in Selkirk \& Lee (2015), Bennett et al. (2016), Bennett \& Elfner (2019).

${ }^{28}$ The statements of MatchWord and MatchPhrase here adopt a formalization in terms of a terminals-based correspondence of syntactic and prosodic constituents, as proposed by Elfner $(2012 ; 2015)$.
} 


\section{MatchWord}

For every instance of a Word in MSO there is exactly one instance of a prosodic word $\omega$ that spells it out phonologically in PI.

Similarly, on the basis of the Phrase-level constituency in 25(a), a matching $\varphi$-level constituency is generated in the PI of 25(b), in response to the phonological spellout condition MatchPhrase (28):

\section{MatchPhrase}

For every instance of a Phrase in MSO there is exactly one instance of a phonological phrase $\varphi$ that spells it out phonologically in PI.

The strongest arguments in favor of positing a categorial distinction between corresponding syntactic and prosodic constituents (Word vs. $\omega$ and Phrase vs. $\varphi$ ) come from mismatches between morphosyntactic constituency and the constituency of phonological output representations which directly affects the phonological patterning observed in the output PO, as well as its phonetic interpretation. The majority of such mismatches appear to be driven by phonological markedness constraints. A simple example of a phonologically driven mismatch is provided by the monosyllabic functional head the in (25), best viewed in Figure 1. It is $\varphi$-initial in the PI representation 25(b), because it is Phrase-initial in the MSO representation 25(a). But it is prosodically encliticized to a preceding $\omega$ in the PO representation 25(c)/Figure $1 .{ }^{29}$ The key to understanding this particular mismatch is the purely phonological markedness constraint STRONGSTART (Selkirk 2011; Bennett et al. 2016), which would be violated by the PI-faithful PO representation $(\sigma \varphi)_{\varphi}$, but not by the actual PO representation $(\omega \sigma)_{\omega}$.

A mismatch between PI and PO will arise when a phonological markedness constraint outranks a phonological faithfulness constraint on the relation between PI and PO. Inputoutput mismatches of various types are a core matter for the phonology (McCarthy \& Prince 1995; 1999). We account for phonology-driven constituency mismatches between MSO and PO by proposing that Match constraints form part of the interface between MSO and PI. A PI supplied with prosodic constituent structure as defined by MatchWord and MatchPhrase forms the crucial link to understanding such mismatches.

An important advantage of our proposal that prosodic constituent structure forms part of the PI representation of the sentence is that it makes it possible to exploit McCarthy \& Prince's theory of faithfulness constraints on the relation between input and output phonological representations as the basis for a theory of possible mismatches between the prosodic constituency of PI and PO. ${ }^{30}$ In section 7, where we discuss the phonological properties of sentences containing [G]-marked and [FoC]-marked constituents, we will see additional advantages of assuming that prosodic constituency at word level and above forms part of the input phonological representation PI.

The following subsections 6.3 and 6.4 are devoted to showing that the presence of prosodic constituency in the phonological output representation PO makes it possible to offer a typologically well-motivated account for the distribution of default tone and default prominence in the all-new sentences of Standard American and British English.

\footnotetext{
${ }^{29}$ See e.g. Selkirk $(1995 / 1996)$ for an account of function word phonology in Standard English.

${ }^{30}$ This proposal goes against Selkirk (2009; 2011), which directly relates the syntactic constituency of MSO to the prosodic constituency of PO.
} 


\subsection{Default tones in all-new sentences}

In standard American and British varieties of English, there are no segmental morphemes that include lexical tone. But there is a rich array of surface tones and tone combinations ('tunes') in non-declarative and pragmatically non-neutral sentences (Ladd 1980; 2008; Pierrehumbert 1980; Gussenhoven 1983; 2004, Pierrehumbert \& Hirschberg 1990; Bartels 1999; Truckenbrodt 2012b). This suggests that these phonologically nonpredictable tonal entities are segment-less tonal morphemes which carry distinct pragmatic meanings. No such tonal morphemes appear in the MSOs of the all-new, pragmatically neutral, declarative sentences that we are considering here.

A generalization that has emerged over time is that the tones in the PO representations of pragmatically neutral all-new declarative sentences in Standard American and British English are (i) H tone 'pitch accents', which are associated with the head/prominent syllable of a phrase level prosodic constituent, and (ii) L 'boundary tones', or 'edge tones', which appear on a syllable at the right edge of a prosodic phrase. These factual generalizations come from accumulated informal observations and from experimental investigations (e.g. Schmerling 1976; Gussenhoven 1983; 1992; 2004, Selkirk 1984; 1995; 2000; Ladd 1996; 2008, Truckenbrodt 1995; 2006; 2007a; Katz \& Selkirk 2011). The surface pattern of $\mathrm{H}$ and $\mathrm{L}$ tone distribution is illustrated in the PO representation of the all-new sentence Sarah mailed the caramels in 25(c), repeated here.

$$
\begin{aligned}
& \text { c. }\left(\left((\text { Sár.ah }) \omega^{\prime}\right) \varphi\left(((\text { máiled }) \omega \text { the }) \omega\left((\text { cár.a.mèls }) \omega^{\prime}\right) \varphi^{\prime}\right) \varphi\right) \imath \\
& \begin{array}{llll}
\mathrm{H} \mathrm{L} & \sim \mathrm{H} & \mathrm{H} & \mathrm{L}
\end{array}
\end{aligned}
$$

The phonological $\varphi$ phrases corresponding to the subject and object noun phrases Sarah and caramels necessarily contain two tones: a high tone $\mathrm{H}$ on the head/prominent syllable of the sole prosodic word $\omega$ in the $\varphi$, and a low tone $L$ on the final syllable of the $\varphi$. The transitive verb mailed, which is not a $\varphi$, predictably carries no L phrase-edge tone in an all-new sentence like (25). It may carry an optional $\sim \mathrm{H}$ tone, however, discussed below.

In many other languages as well, tones which have no lexical or morphemic status appear predictably, 'by default', in PO representations. It is not uncommon for a $\mathrm{H}$ tone to be predictably associated with the head syllable of every prosodic word $\omega$ in any sentence of some language. Cairene Arabic (Hellmuth 2006; 2007) offers a particularly well-studied example. It is also not uncommon for the head syllable of a phonological phrase $\varphi$ to be predictably associated with a $\mathrm{H}$ tone. An example is modern Irish (Elfner 2012; 2015). Kolkata Bengali is an example of a language where it's a predictable L tone that appears on the head syllable of any $\varphi$ in all-new sentences (Hayes \& Lahiri 1991). Several varieties of German also show an $\mathrm{L}$ tone on the phrasal head, with a $\mathrm{H}$ tone at the right phrase edge (Truckenbrodt 2002). Truckenbrodt (2006; 2007b) and Ladd (1996; 2008) argue that the presence of accent tone is predicted by the distribution of phrasal prominence ('stress').

In an optimality theoretic phonology the appearance of predictable elements in the phonological output is driven by phonological markedness constraints (Prince \& Smolensky 1993; 2004; McCarthy \& Prince 1995; 1999). Markedness constraints collectively define the 'ideal', unmarked, PO form of a sentence. Faithfulness constraints, on the other hand, call for identity between PI and PO representations. They ensure that the distinctive lexical (meaning-tied) phonological properties of the PI are retrievable from the PO representation. In OT, it is a language-particular ranking of universal phonological markedness and faithfulness constraints which determines whether and under what prosodic conditions a predictable, 'default', tone will be inserted (epenthesized) on a syllable of the PO representation.

The widely attested predictable appearance of tone on a prosodically prominent syllable is evidence that the universal set of phonological markedness constraints on PO 
representations must include constraints which call for a prosodic head prominence to be associated to some tone (deLacy 2002; Yip 2002; 2007; Elordieta \& Selkirk 2018). A phonological markedness constraint like $\operatorname{HEAD}(\varphi)$ :TONE in (29) below would have responsibility for the predictable epenthesis of the tone commonly referred to as a $\mathrm{H}$ 'pitch accent' associated with phrasal head/prominence in all-new sentences in English. In languages like English, $\operatorname{HEAD}(\varphi)$ :TONE would be higher ranked than the tonal inputoutput faithfulness constraint that would rule out any presence of a tone in the output that is not already present in the input (Myers 1997).

\section{HEAD-OF- $\varphi$-HAS-TONE [HEAD $(\varphi)$ :TONE]}

The head syllable $\left(\sigma^{\prime}\right)$ of a phonological phrase $(\varphi)$ must be associated with tone. The head syllable of a phonological phrase is the head syllable of the head foot of the head prosodic word of a phonological phrase.

Preference for it to be a $\mathrm{H}$ tone that is associated with a prosodic head, whether alone (as in English H) or in combination with a L tone (as in Tokyo Japanese HL), could be independently specified by further phonological markedness constraints (de Lacy 2002). ${ }^{31}$

Additional evidence for the existence of a universal phonological markedness constraint like $\operatorname{HEAD}(\varphi)$ :TONE comes from other, very different, types of tonal phenomena. In the Bantu languages Digo (Kisseberth 1984) and Giryama (Volk 2011: 17), a lexical $\mathrm{H}$ tone associated with a morpheme in a nonfinal word of a $\varphi$ in PI is shifted rightwards in PO to the penultimate syllable of the final word of that $\varphi$. In that $\varphi$, the phrasal penult syllable is plausibly the head syllable $\sigma^{\prime}$ of the $\varphi$ (Hyman 2011; 2019). The tone shift thus allows for the satisfaction of $\operatorname{HEAD}(\varphi)$ :TONE in PO. In the so-called pitch accent language Lekeitio Basque, where morphemes are lexically distinguished in PI by whether they are 'accented' (that is, tone-bearing) or not, any lexical accent tone(s) of morpheme(s) within a word must be realized in PO on the (plausibly stressed) penultimate syllable of that word and nowhere else in the word (Hualde et al. 1994; Elordieta \& Selkirk 2018).

The epenthesis of a $\mathrm{H}$ tone onto the head syllable of $\varphi$ in Standard American and British English, the shift of lexical $\mathrm{H}$ tone to the head syllable of $\varphi$ in Digo and Giryama, and the shift of a lexical $\mathrm{H}$ tone to the head syllable of a prosodic word $\omega$ in Lekeitio Basque are all a matter of the phonology per se. We propose to see them as language-particular responses to the need to satisfy universal phonological markedness constraints like $\operatorname{HEAD}(\varphi)$ :TONE or $\operatorname{HEAD}(\omega)$ :TONE. In the phonological constraint ranking of languages like Digo or Lekeitio Basque, where tone spreads or shifts instead of being epenthesized, any faithfulness constraint(s) calling for the toned or toneless status of a tone-bearing unit in PI to be the same in PO must then be lower ranked than a markedness constraint like $\operatorname{HEAD}(\varphi)$ :TONE or HEAD $(\omega)$ :TONE (see Myers 1997).

Another family of phonological markedness constraints that plays a role in determining the default surface distribution of tone in Standard American and British English involves the edges, or boundaries, of prosodic constituents. The sentence in (25), with its predictable L tones at the right edge of the phonological phrases (Sarah) and (mailed

\footnotetext{
${ }^{31}$ In some varieties of English, a predictable, epenthetic, $\mathrm{L}$ accent tone before the morphemic $\mathrm{H}$ edge tone appears in a yes-no question. Arguably the Obligatory Contour Principle (OCP) rules out sequences of identical tones within a $\varphi$ in these varieties. The lexical $\mathrm{H}$ quality of the morphemic edge tone is preserved by a tonal faithfulness constraint while satisfying $\operatorname{HEAD}(\varphi)$ :TONE together with the OCP results in a $\mathrm{L}$ accent tone that is epenthesized in this case. See Hayes \& Lahiri (1991) and Selkirk (2007) on the role of the OCP in determining the quality of predictable tonal accents in Bengali.
} 
the (caramels)), provides motivation for (30), a markedness constraint targeting the right edge of $\varphi .^{32}$

RIGHT-EDGE-OF- $\varphi$-HAS-TONE [R-EDGE( $\varphi)$ :TONE]

The syllable at the right edge of a $\varphi$ must be associated with some tone. ${ }^{33}$

It is very common crosslinguistically for there to be a predictable appearance of some tone or tonal complex at the right or left edge of a phrase in the surface prosodic structure representation of a sentence (see e.g. Beckman \& Pierrehumbert 1986; Gussenhoven 2004; the papers in Jun 2005; 2014; Féry 2017). The phonological markedness constraint (30) can be seen as providing the pressure for the predictable insertion/epenthesis of a default edge tone at the right edge of a $\varphi$ in Standard American and British English. Looking beyond languages like English, which lack lexical tone, (30) could also be seen as responsible for the special variety of rightward $\mathrm{H}$ tone spread in Copperbelt Bemba reported in Kula \& Bickmore (2015). There a lexical $\mathrm{H}$ tone spreads rightward from its underlying position in PI through a sequence of toneless syllables within a $\varphi$ in PO, but only if it can reach a toneless syllable that is in final position in that $\varphi$. There is no spreading at all from its underlying source position if that $H$ tone can't reach the right edge of $\varphi-$ due to the presence of a lexical $\mathrm{H}$ tone in $\varphi$-final position, for example. This suggests that this spreading is the consequence of the requirement expressed in the constraint (30) that in PO there be some tone on the syllable at the right edge of a $\varphi$. If the demand is already met by the presence of an underlying tone associated with the final syllable of a $\varphi$ in PI, then there's no pressure for a tone located earlier in the $\varphi$ in PI to spread from the left in order to satisfy R-EDGE( $\varphi$ ):TONE in PO.

Finally, there's a third type of predictable, default, epenthetic tone in all-new sentences of Standard American and British English. Recall that a $\mathrm{H}$ tone may optionally appear on the verb mailed preceding the necessarily pitch-accented direct object in 25(c). It has already been observed (e.g. Gussenhoven 1992; 2004; Ladd 1996; 2008) that in Standard American and British English additional accent tones may optionally appear preceding, but not following, the 'nuclear accent' that is associated with the head/'main prominence' of a $\varphi$. We should thus entertain the possibility that these optional tones in Standard English represent a third category of epenthetic tone, introduced by a constraint with the properties of (31).

HEAD-AT-LEFT-EDGE-OF- $\varphi$-HAS-TONE [HD@L( $\varphi)$ :T]

The closest prosodic head to the left edge of a $\varphi$ is associated with some tone.

As Gussenhoven (2004: 285) points out, in a recursive $\varphi$ structure like the one that characterizes (mailed the (caramels) $\varphi) \varphi$ in (25), where the verb mailed lies at the left edge of a $\varphi$, its first (and only) stressed syllable could - but only optionally - receive an 'edge-accent' $\mathrm{H}$ tone. In its optionality and in its restriction to a left- $\varphi$-edge word in Standard American and British English, ${ }^{34}$ this epenthetic edge accent tone is distinct from the nuclear accent tone that appears on the head syllable of a $\varphi$.

\footnotetext{
32 Barnes et al. (2010) point to some variability in the precise phonetic alignment position of the phrasal rightedge L boundary tone in Standard American English.

${ }^{33}$ The quality (L vs. H) of the edge tone is not specified in (30); it is sometimes contextually predictable on the basis of the quality of the preceding pitch accent, or the tonal quality of the pitch accent may determine the quality of the edge tone, depending on the language.

${ }^{34}$ A promising approach to the characterization of optionality or variation in the pitch accent epenthesis due to the positionally-sensitive phonological markedness constraint (31) is seen in the optimality theoretic accounts by A. Kaplan (2016) of variation in flapping in standard American English and schwa deletion in standard French.
} 
There is crosslinguistic motivation for the sort of edge-accent called for in (31). A simultaneous appeal to a righthand phrase edge and a lower-level prosodic prominence nearest to that edge characterizes the sort of post-nuclear 'phrase accents' which Grice, Ladd \& Arvaniti (2000) document for various languages of Eastern Europe. Moreover, Elfner (2012; 2015) shows that in Connemara Irish, along with the $\mathrm{H}$ tone that always appears on the prosodic head of the final word in any $\varphi$, there is a LH tonal complex that obligatorily appears on the head syllable of the $\omega$ lying at the left edge of a nonminimal $\varphi .{ }^{35}$

Summing up, the distribution of the tones of all-new, pragmatically neutral, declarative sentences in Standard English is characterizable via crosslinguistically supported phonological markedness constraints targeting the relation between tone and prosodic structure in PO representations. This phonological markedness approach meshes well with the recent proposal of Torreira \& Grice (2018) that metrical/prosodic structure plays a role in determining the association properties of 'intonational tones' in languages without lexical tone.

\subsection{Prosodic head prominence}

The PO representations 25(c) and Figure 1 (the tree version is repeated below) contain representations of prosodic headedness or prominence.

The formal status of a prosodic constituent as a prosodic head or prominence of a higher prosodic constituent is abstract, but it comes with a broad variety of phonological and/or phonetic consequences, depending on the language. As we've just seen, in all-new, pragmatically neutral, declarative sentences in Standard American and British English, a phonological consequence of prosodic headedness is the appearance of a predictable $\mathrm{H}$ tone on the head syllable of a phonological phrase. Moreover, in Standard American and British English, the prosodic head status of a syllable within a foot $(f)$ or a prosodic word $(\omega)$ - with or without accent tone - is interpreted by the phonetics with degrees of duration reflecting its hypothesized degrees of abstract prominence (see e.g. Sugahara 2012). Duration patterns reflecting higher levels of prominence are seen as well in the Katz \& Selkirk (2011) data on phrasal prominence and FoCus, which we will come back to in section 7. ${ }^{36}$ By comparison, Standard Japanese, for example, shows no such durational effect on syllables with accent tone (Beckman 1982; 1986), even though tonal pitch accent is arguably associated with prosodic headedness or prominence in Standard Japanese (Ito \& Mester 2016; Elordieta \& Selkirk 2018). Both the predictable epenthesis/insertion of prominence-dependent accent tones in Standard British and American English and the phonetic interpretation of prominence as duration (and other phonetic properties) require us to assume that prosodic head prominence is represented in the PO representation of the phonology. The question is how this abstract prosodic prominence becomes a property of the PO of all-new sentences.

We would expect that predictable prosodic head prominence ('stress') is only represented in the PO representation of all-new sentences of Standard British and American English, and this is reflected in the MSO-PI-PO triple for (25) introduced earlier.

Sarah mailed the caramels

a. Morphosyntactic output representation (MSO):

$\left.\left[\left[\text { Sarah }_{\mathrm{N}}\right]_{\mathrm{NP}}\left[[\text { mail-ed }]_{\mathrm{V}}\left[\text { the }[\text { caramel-s }]_{\mathrm{N}}\right]_{\mathrm{NP}}\right]_{\mathrm{DP}}\right]_{\mathrm{VP}}\right]_{\text {Clause }}$

b. Phonological input representation (PI):

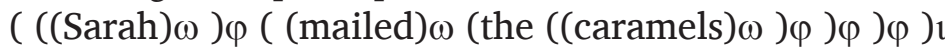

\footnotetext{
${ }^{35}$ See Ito \& Mester $(2012 ; 2013)$ for the notion of a non-minimal prosodic word.

${ }^{36}$ Note that in Figure 1 neither one of the $\varphi$ daughters of $\imath$ is a head $\varphi$ '. This absence of head status for the $\varphi$ daughters in the 1 of this all-new sentence is suggested by the patterns of relative duration between successive $\varphi$ in a sentence that are observed in Katz \& Selkirk (2011) and discussed in section 7.
} 
c. Phonological output representation (PO):

$$
\left(\left((\text { Sár.ah }) \omega^{\prime}\right) \varphi\left(((\text { máiled }) \omega \text { the }) \omega\left((\text { cár.a.mèls }) \omega^{\prime}\right) \varphi^{\prime}\right) \varphi\right) \imath
$$

$\begin{array}{llll}\mathrm{H} \mathrm{L} & \sim \mathrm{H} & \mathrm{H}\end{array}$

A purely phonological, entirely general, characterization of prosodic headedness that applies to any prosodic constituent that dominates another prosodic constituent is definable for PO representations. Just as a foot has a unique most prominent head (a 'stressed syllable'), so a phonological phrase $(\varphi)$ has a unique prominent head $\omega$ (which contains the 'nuclear stressed' syllable of the $\varphi$ ), and so on. HEAD-PROMINENCE-IN- $\varphi$ in (32) is one example of a relevant constraint.

\section{HEADPROMINENCE-IN- $\varphi$ [HDPROM-IN- $\varphi$ ]}

Every $\varphi$ has exactly one prominent daughter, its head.

HEADPROMINENCE-IN- $\varphi$ belongs to a larger family of phonological markedness constraints that call for a head/prominence within prosodic constituents of all types that dominate another prosodic constituent, be they $f, \omega, \varphi$, or 1 . It has been recently argued that phonological constraints that assign prosodic headedness are violable (Ito \& Mester 2016; Elordieta \& Selkirk 2018). This violability supports the notion that headedness is assigned by a phonological markedness constraint and is not part of the necessary 'hardware' of prosodic constituents. ${ }^{37}$

Truckenbrodt $(1995 ; 2006 ; 2007 a)$ makes a case for the descriptive generalization behind HEAdPROMinENCE-IN- $\varphi$ in Standard American and British English. The generalization is that, by default, every syntactic phrase of a sentence contains a stress/prominence associated with a pitch accent. For Truckenbrodt, the generalization is accounted for via a syntax-phonology interface constraint, Stress XP, that directly links syntactic representations to phonological output representations: Each XP of a sentence corresponds to a phonological phrase containing stress (Truckenbrodt 2006). But Stress XP is superfluous in a theory of prosodic constituent structure representation like the one assumed here, in which the Phrase structure of MSO is spelled out by MatchPhrase as the (potentially recursive) $\varphi$ structure of prosodic structure representation. Our HEADPROMINENCE-IN- $\varphi$ is an instance of a general set of markedness constraints calling for head prominence that hold of all levels of prosodic structure, including the purely phonological foot. In other words, Truckenbrodt's generalization can now be captured via an independently needed account of the morphosyntactic-prosodic constituency relation and a general theory of the distribution of prosodic prominence within prosodic constituents of the various types $f, \omega, \varphi$, or 1 .

The question still remains why it is that the head prominence of the $\varphi$ corresponding to the VP in (25(c))/Figure 1 is the $\varphi^{\prime}$ corresponding to the object rather than the $\omega$ corresponding to the verb. This is a general pattern. As Cinque (1993) and Truckenbrodt (1995; 2006; 2007a) have pointed out, in German transitive sentences the verb (a word) will never have greater prominence than its sister phrase, regardless of the linear order in which they appear. Kahnemuyipour (2009) gives crosslinguistic support for this generalization. This generalization suggests an additional phonological markedness constraint determining which one of multiple daughters of a prosodic category node has the status of head.

\footnotetext{
${ }^{37}$ Note that the absence of head status for either daughter $\varphi$ of $\imath$ in Figure $1 /(25 c)$ - marked by absence of a superfix accent mark on these $\varphi$ - would mean that the -level constraint HEADPROMINENCE-IN- 1 is violated in PO. This violation could be the result of the higher ranking of a prosodic faithfulness constraint requiring that the head status of any $\varphi$ daughter of $\imath$ in PO must correspond to head status for the corresponding $\varphi$ within a corresponding 1 of PI.
} 
HEAVYSISTERPROMINENCE [HVSISPROM]

When sisters within a prosodic constituent are of unequal prosodic category, the heavy sister is the head.

The heavy sister is the constituent whose category is higher in the prosodic hierarchy.

HEAVYSISTERPROMINENCE imposes head status for the object phrase (caramels) $\varphi^{\prime}$ within the $\varphi$ corresponding to the VP in (25). Importantly, HVSISPROM makes the general prediction that the higher, 'heavier', prosodic category type will be the head: in a prosodic word consisting of a foot and a syllable, it calls on the foot to be the head; in a recursive $\omega$ structure where a $\omega$ dominates another $\omega$ and a clitic $\sigma$, the sister $\mathrm{w}$ would be the head, and so on, regardless of order.

Summarizing this section as a whole, we have seen that the distribution of phrasal head prominences and of accent and edge tones in the phonological output representations of all-new pragmatically neutral sentences in Standard American and British English is phonologically predictable on the basis of the morphosyntactic output structure (MSO) of a sentence. A system of independently motivated interface Match constraints yielding prosodic constituency in PI and a system of prosodic-structure-sensitive markedness constraints in the phonology have key roles in explaining the presence and location of prominence and tone properties in PO. This means that the phonological system of Standard American and British English generates the output prosodic properties of all-new sentences from their morphosyntactic output representations without any appeal to newness, or to any other information structure notion for that matter.

\section{Spelling out [FoC] and [G] in Standard American and British English}

It's generally recognized that focus and givenness in Standard American and British English are phonologically realized in terms of prominence, or the lack of it. Section 2 established that both [FoC] and [G] are syntactically well-motivated features. Crosslinguistically, they can trigger displacement and agreement or license ellipsis. As syntactically represented features, the two features should also be able to influence the mapping from syntactic structure to phonological representation at the syntax-phonology interface. However, beyond the syntax-phonology interface, we would expect the phonology, and the phonology alone, to determine the final output. In this section we present an account of English prosody that conforms to those expectations within the MSO-PI-PO model of sentence phonology introduced in the previous section.

\subsection{Spelling out [FoC]}

Our account honors the longstanding insight that in Standard American and British English the focus of a sentence is the locus of greatest prominence, where this prominence has been defined as the main (nuclear) stress of a sentence (Jackendoff 1972), as the constituent that is dominated by an unbroken chain of strong (S-labelled) nodes in the metrical tree mirroring the syntactic structure of a sentence (Ladd 1980, and many others), or as the prosodic constituent that is more prominent than any other within the domain of a focus (Truckenbrodt 1995).

Within our framework of assumptions, the prosodic impact of [FoC] in Standard American and British English would have to be a spellout constraint affecting the mapping from MSO to PI and it would be expected to be a constraint on prosodic structure. We propose that a [FoC]-marked constituent at MSO is spelled out as an t-level head in PI. ${ }^{38}$

\footnotetext{
${ }^{38}$ Implementing Truckenbrodt's alternative proposal that it is the focus domain not the intonational phrase 1 that is relevant to defining the prominence for [FoC]-marked constituents would be theoretically unattrac-
} 
a. Morphosyntactic Output ${ }^{39}$

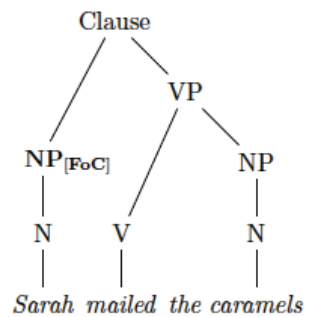

b. Input phonological representation (PI)

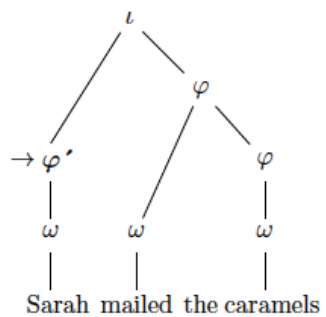

c. Output phonological representation (PO)

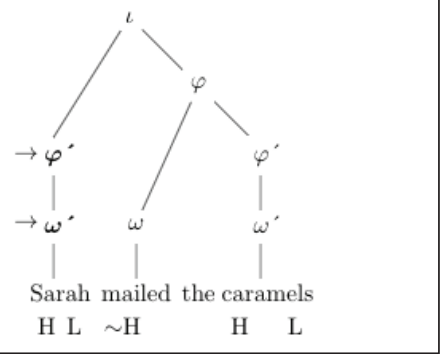

Figure 2: Derivation for sentence with [FoC] subject.

$[$ FoC $]=\imath$-Level-Head

A [FoC]-marked constituent of MSO is spelled out as an t-level head in PI.

An -level head is a link in a chain of prosodic heads that ends in the prosodic head of 1 .

The proposal in (34) presumes that a sentence (Clause) constituent in MSO is spelled out as an $\mathrm{i}$ by MatchClause, one in the family of constituency spellout constraints that relates MSO and PI.

\section{MatchClause}

For every instance of a Clause of MSO there is exactly one instance of an intonational phrase $\imath$ that spells it out phonologically in PI.

Since a prosodic constituent like 1 can have at most one prosodic head, it follows from (34) that a $[\mathrm{FoC}]$-marked constituent will be more prominent than any other in the same 1 .

By way of illustration, consider the case of subject FoCus in Figure 2. The non-FoCus constituents in this example are new in the discourse, not Given. The sentence in Figure 2 could be spoken in a context where mailed the caramels is not Given in the current discourse, hence not [G]-marked, and where Sarah's having mailed the caramels is being contrasted with possible alternatives like Ewan's or Allie's having done so.

In Figure 2 above, r-level heads are indicated by an arrow and are marked in bold. Figure 2(b) only includes the head prominence that spells out [FoC] in the MSO Figure 2(a). This prominence has to be maintained in the PO Figure 2(c). ${ }^{40}$ The other prominences in Figure 2(c) are there by default, hence are not present in the PI Figure 2(b).

tive within our framework of assumptions. Prosodic i-structures would have to be stipulated to represent FoCus domains, that is, they would have to be stipulated to have representational properties that serve the exclusive needs of languages that realize FoCus prosodically.

${ }^{39}$ For graphic convenience, the MSO representations of the sentence Sarah mailed the caramels in this section will not include any functional projections. The DP dominating the is therefore absent.

${ }^{40}$ To ensure the appearance in PO of the t-level heads that spell out [FoC] in PI, a prosodic faithfulness constraint requiring t-level heads of PI to correspond to t-level heads of PO must be higher ranked than any other constraints which might weigh against the presence of those t-level heads in PO. 
The prosodic properties of the PO representation of a sentence containing a [FoC]marked constituent are thus only partly determined by the greater prominence of the [FoC]-marked constituent. In sentences where a [FoC]-marked phrase and phrases that are merely new cohabit, the default phonology supplies $\varphi$-level prominence for those merely new constituents and for the [FoC]-marked constituent as well. The result is that in the PO representation, both [FoC]-marked and merely new constituents carry the tonal pitch accents supplied by the phonology to the prominent $\omega$ ' head of a $\varphi$. What distinguishes [FoC]-marked from merely new, unmarked, constituents is the status of their corresponding $\varphi$ as an t-level head prominence in PI. That prominence in PO is inherited from PI.

The necessity of making a distinction between FoCus and merely new, and the possibility of combining them in the same sentence, has largely gone unrecognized in the previous literature on the phonology and phonetics of sentences containing a FoCus. ${ }^{41}$ Most studies have examined sentences where a FoCus is preceded and/or followed by Given constituents, which lack both $\varphi$-level prominence and pitch accenting. But, as pointed out in Katz \& Selkirk (2011), it is only by investigating combinations of FoCused and merely new constituents in the same sentence that it can be established that it is the higher prominence, or 'stress', of a FoCused constituent that is grammatically distinctive. ${ }^{42}$

Katz \& Selkirk (2011) provides phonetic evidence for the generalization that a [FoC]marked constituent carries the highest level of prominence in a sentence. They investigate the phonetic properties of sentences with [FoC]-marked constituents that precede or follow non-[FoC]-marked, merely new, constituents in minimal triplets like those in (36). The results show that the PO representations of both post-verbal phrases in 36(a), 36(b) and 36(c) show the typical default $\mathrm{H} L$ tone pattern of a $\varphi$, whether or not one or the other phrase, or neither, is also [FoC]-marked. What distinguishes the three configurations are statistically significant phonetic differences in relative pitch, duration and intensity.

PO with phonetic pitch downstep/upstep patterns (Katz \& Selkirk 2011)

(a) FoC-New: ${ }^{43}$

( They only ( ( produced $)_{\omega^{\prime}}\left((\text { línen })_{\omega^{\prime}}\right)_{\varphi^{\prime}}$ in $\left.\left.\left((\text { Níneveh })_{\omega^{\prime}}\right)_{\varphi}\right)_{\varphi^{\prime}}\right)_{1}$

$\mathrm{H} \quad \mathrm{L} \quad \forall \mathrm{H} \quad \mathrm{L}$

(b) New-FoC:

( They only ( ( produced $)_{\omega}\left((\text { línen })_{\omega^{\prime}}\right)$ in $\left.\left.\left((\text { Níneveh })_{\omega^{\prime}}\right)_{\varphi^{\prime}}\right)_{\varphi^{\prime}}\right)$,

$\mathrm{H} \quad \mathrm{L} \quad(\uparrow) \mathrm{H} \quad \mathrm{L}$

(c) New-New:

( They ( ( produced ) $\left.)_{\omega^{\prime}}(\text { línen })_{\omega^{\prime}}\right)_{\varphi}$ in $\left.\left.\left((\text { Níneveh })_{\omega^{\prime}}\right)_{\varphi}\right)_{\varphi}\right)_{\text {I }}$

$\mathrm{H} \quad \mathrm{L} \quad \downarrow \mathrm{H} \quad \mathrm{L}$

Drawing on a rich literature, Katz \& Selkirk (2011) discuss the pitch scaling effects in triples like those in (36). In 36(a) the considerable downstepping ( $\downarrow$ ) between the FoCused direct object, and the following merely new phrase testifies to a higher level of prosodic prominence for the FoCused constituent (Gussenhoven et al. 1997; Truckenbrodt 2004). In the

\footnotetext{
${ }^{41}$ Exceptions are Selkirk (2002; 2008), Neeleman \& Szendrői (2004), Féry \& Samek-Lodovici (2006), and Truckenbrodt (2012a).

${ }^{42}$ Katz \& Selkirk (2011) use the term 'contrastive focus' to refer to FoCus and the term 'informational focus' to refer to merely new constituents.

${ }^{43}$ As FoCus-New examples like those in 36(a) make clear, there is no post-FoCus 'deaccenting', 'destressing' or 'dephrasing' in Standard American and British English, contrary to what is widely assumed (e.g. in Büring's 2016 textbook). See also Kügler \& Féry (2017) for German, and Ishihara (2007; 2011) for Japanese. PostFoCus 'destressing', 'deaccenting', or 'dephrasing' could be a language-particular phonological effect in some languages. In Standard American and British English, it is a consequence of the [G]-marking of a constituent.
} 
New-FoCus case 36(b), the lack of downstep, or presence of an optional small upstep ( $\uparrow$ ), again implies greater prominence for the FoCused phrase (Ladd 1996/2008; Gussenhoven 2004). An overall, non-prominence-sensitive, default pitch downtrend which is present in any sentence (van den Berg et al. 1992; Truckenbrodt 2004) explains the lesser pitch height of the FoCus. In the all-new case 36(a), by comparison, the significantly different, but small degree of default downstepping $(\downarrow)$ between the two post-verbal phrases is consistent with a PO representation where neither $\varphi$ carries i-level prominence, suggesting that, in the default case of all-new sentences, an t-level head prominence is not defined. This suggestion is in line with the conclusion by Ladd (2008: 257) that "there is no phonetic justification for treating the last accent of a sentence [of an all-new sentence] as more prominent." Frota (2000) reports a similar finding for European Portuguese.

We assume here that the presence of head prominence in a prosodic constituent of PO is called for by phonological markedness constraints and so may be found in constituents at any level of the prosodic hierarchy. This means that the apparent lack of t-level head prominence for $\varphi$ daughters of $\imath$ in all-new sentences like 36(c) requires an explanation. Our suggestion is that, in the phonological constraint ranking of English, the markedness constraint HeadProminence-in- 1 , which calls for head prominence in $\mathrm{l}$, is subordinated to a prosodic faithfulness constraint that prohibits the presence in PO of any t-level head prominence not present in PI. As a consequence, only t-level heads required by the spellout of [FoC]-marking in PI would be present in PO. The absence of any t-level 'nuclear stress' on the rightmost $\varphi$ in the all-new 36(c) would thereby be explained.

Summarizing, it is just FoCused constituents, rather than merely new ones, that are given distinctive phonetic salience in Standard American and British English. On our account, this can be ascribed to (i) their being spelled out as t-level heads in PI, in accordance with the spellout constraint $[\mathrm{FoC}]=\mathrm{t}$-Level-Head, and (ii) their corresponding -level head-prominence in PO, faithfully inherited from PI.

Sentences with multiple [FoC]-marked constituents present a challenge for the proposal that a [FoC]-marked constituent of MSO corresponds to a t-level-head in PI. Assuming an inviolable constraint saying that a prosodic constituent can have at most one head, only one daughter of an 1 can be the head of that 1 . The two conjuncts in (37) illustrate the problem: each conjunct sentence in (37) has a [FoC]-marked verb followed by a [FoC]marked object.

You: What does Imelda do all day long?

Me: She $[\text { hammers }]_{\mathrm{FoC}}[\text { nails }]_{\mathrm{FoC}}$ and she $[\text { screws in }]_{\mathrm{FoC}}[\text { bolts }]_{\mathrm{FoC}}$

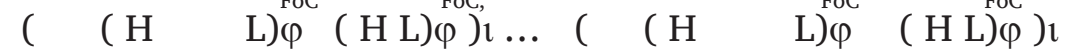

The spellout constraint FoCus $=\imath$-Level-Head requires that each $[\mathrm{FoC}]$-marked constituent be an t-level-head in PI, but this would be impossible in Dual FoCus cases like (37), unless each conjunct was broken up into two $\mathrm{\imath}$ in PI. To our ear, there seems to be no phonetic 'disjunction' between the two $\varphi s$ in the conjuncts of (37), however. It looks like there is just a single 1 . Moreover, it does not seem, to our ear, that either of the two FoCi is systematically more prominent than the other. If future experimental investigation confirms our impression, we could assume that FoCus $=1$-Level Head goes unsatisfied with one of the two [FoC]-marked constituents, and we will need to search for an explanation for this.

The tonal facts of (37) suggest nonetheless that at this point more can be said about multiple FoCus cases. In (37) all four [FoC]-marked constituents (the V and NP of each conjoined sentence) have an obligatory $\mathrm{H}$ accent tone, indicating that both verbs and both nouns bear at least $\varphi$-level prominence. Moreover, each of the four [FoC]-marked constituents in (37) shows the characteristic L edge tone indicating $\varphi$-final position in PO. Each [FoC]-marked verb, then, should correspond to a headed $\varphi$ in PO, just like each 
[FoC]-marked object phrase. This is a significant fact, since, given the status of verbs as mere Words in MSO, we would expect them to have mere $\omega$ status in PI. The 'promotion' of the verbs to $\varphi$ status in double FoCus cases like (37) must therefore be an effect of their being [FoC]-marked. This effect could be due to an additional spellout constraint for $[\mathrm{FoC}]$ that would apply at the $\varphi$ level, namely $[\mathrm{FoC}]=\varphi$-Level-Head. For $[\mathrm{FoC}]$-marked verbs in MSO to satisfy $[\mathrm{FoC}]=\varphi$-Level-Head in PI, their $\varphi$-level head status would have to be introduced in PI. That is, in PI the [FoC]-marked verb would both have the status of a $\varphi$ and be the prominent $\omega^{\prime}$ that is the head of that $\varphi$ And, assuming that the $\varphi s$ and heads of $\varphi s$ of PI are faithfully inherited as corresponding $\varphi s$ and heads of $\varphi s$ in PO, their $\mathrm{H}$ accent tone and the $\mathrm{L}$ edge tone to their right in $\mathrm{PO}$ would be explained.

Summarizing, multiple FoCus cases like (37) suggest that the spellout of [FoC]-marking is not limited to $[\mathrm{FoC}]=\imath$-Level Head. $[\mathrm{FoC}]=\imath$-Level Head seems to be just one of a family of Syntax-Phonology interface constraints that also includes $[\mathrm{FoC}]=\varphi$-Level Head, and even $[\mathrm{FoC}]=\omega$-Level Head, as we will argue in 7.3. In general, we are proposing that languageparticular choices of spellout constraints for the phonological expression of [FoC]-marking determine the input phonological representation for the phonology per se, where languageparticular rankings of relevant prosodic markedness and faithfulness constraints determine the character of the PO representation which is submitted to phonetic interpretation.

A comparison to the spellout, phonology, and phonetics of focus in Mandarin Chinese discussed in Kabagema-Bilan et al. (2011) supports this approach to the spellout of FoCus in terms of head prominence and to its phonological and phonetic interpretation. Their study targets the prosodic properties of sentences with multiple focus constituents in Mandarin Chinese. Unlike English, in Mandarin Chinese, the tone borne by a word in PO is an idiosyncratic lexical property; it is not present as a reflex of head prominence at either word or phrase level. Xu (1999) found that in all-new subject-verb-object sentences containing a sequence of words with only lexical $\mathrm{H}$ tones the $\mathrm{F}_{0}$ contour is absolutely flat, with no pitch protrusion anywhere. By contrast if the same type of sentence has a focused constituent, it shows a significant $\mathrm{F}_{0}$ peak in relation to the surrounding $\mathrm{H}$-tone words. Kabagema-Bilan et al. (2011) go on to examine H-tone-word sentences containing two focused constituents. They find that both of the focus constituents show a significant $\mathrm{F}_{0}$ peak, and that the rightmost of the two peaks is significantly higher than the first. This result is interpreted as showing (i) that each of the two focus constituents must carry prosodic prominence/stress at the phonological phrase $(\varphi)$ level and (ii) that t-level prominence is placed on the rightmost of the two constituents bearing $\varphi$-level prominence.

\subsection{Spelling out [G]}

The prosody of Given constituents has been described as absence of prominence or 'stress', whether in the metrical structure formulation of 'stress shift away from given' of Ladd (1980), or in the Destress Given constraint of Féry \& Samek-Lodovici (2006). Positing Destress Given as the constraint that spells out [G]-marking in PI would not be implementable in our approach, however, because no distinction could be made between a [G]-marked and a merely new constituent in PI. Neither [G]-marked nor merely new constituents would have $\varphi$-level prominence in PI, but both would get $\varphi$-level prominence by default in PO. Destress Given is not an option, then. We propose instead that a [G]-marked constituent in MSO is spelled out with a lack of $\varphi$ status in PI. Lack of prominence would follow from the lack of $\varphi$ in PO, inherited from PI. We might dub this spellout constraint for [G]-marking in Standard American and British English 'DephraseGiven'.

$[G]=$ No- $\varphi$ (DephraseGiven)

A [G]-marked constituent in MSO corresponds to a prosodic constituent in PI which is not a $\varphi$ and contains no $\varphi$. 
(38) has further empirical consequences. Recall that the $\varphi$ status of a PO constituent is responsible for the presence of an obligatory $\mathrm{H}$ accent tone and for the presence of the $\mathrm{L}$ edge tone at the right edge of $\varphi$ in Standard American and British English. If a [G]-marked constituent lacks $\varphi$ status in PI, then, the corresponding constituent in PO should lack both the $\mathrm{H}$ accent tone and the $\mathrm{L}$ edge tone. These predictions are borne out.

The three sentences in (39) show contrasts in the distribution of tone, even though they differ only with respect to [G]-marking:

a. All-new sentence

MSO: $\left.\quad[\text { [ Sarah }]_{\mathrm{NP}}\left[\text { mailed }\left[\text { the }[\text { caramels }]_{\mathrm{NP}}\right]_{\mathrm{DP}}\right]_{\mathrm{VP}}\right]_{\text {Clause }}$ PO(tones): $\quad \mathrm{H} \quad \mathrm{L} \quad \sim \mathrm{H} \quad \mathrm{H} \quad \mathrm{L}$

b. Given subject, otherwise all-new

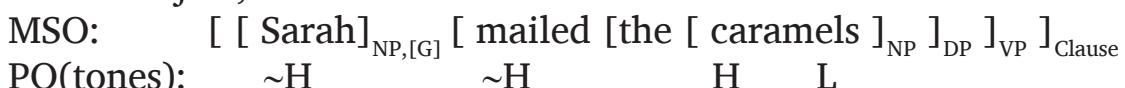

c. Given object, otherwise all-new

MSO: $\left.\quad[\text { [ Sarah }]_{\mathrm{NP}}\left[\text { mailed }\left[\text { the }[\text { caramels }]_{\mathrm{NP},[\mathrm{G}]}\right]_{\mathrm{DP}}\right]_{\mathrm{VP}}\right]_{\text {Clause }}$

PO(tones): $\quad \mathrm{H} \quad \mathrm{L} \quad \mathrm{H} \quad \mathrm{L}$

39(b) and (c) contain a [G]-marked phrase in subject and object positions respectively. A suitable discourse context for 39(b) might be one where we have just been talking about Sarah when a text message arrives on my phone, and I report to you what that message says. Sarah would be Given in that context. Assuming that there has been no mention of mailing the caramels in that particular discourse (even though the issue is a familiar one), the VP mailed the caramels would count as new.

Ladd (2008: $300 \mathrm{ff}$.) discusses the tonal properties of Given subject phrases and their implications for a prosodic structure analysis. Here is how his observations might apply to 39(b) when adapted to our framework of assumptions. First, there is no obligatory $\mathrm{H}$ accent tone on the [G]-marked subject. This indicates absence of phrasal stress, hence absence of head/prominence of $\varphi$, hence absence of a head $\omega^{\prime}$ (marked with an arrow in the tree Figure 3 below). Second, there is no L edge tone at the right edge of the [G]-marked subject. This indicates the absence of $\varphi$ constituent status. The optional $\sim \mathrm{H}$ at the left edge of the sentence as a whole must be an edge accent, coinciding here with the left edge of $t^{44}$ In sum, then, the 'dephrasing' induced by [G] explains the particular prosodic properties of Sarah in 39(b), which is given in tree form in Figure 3.

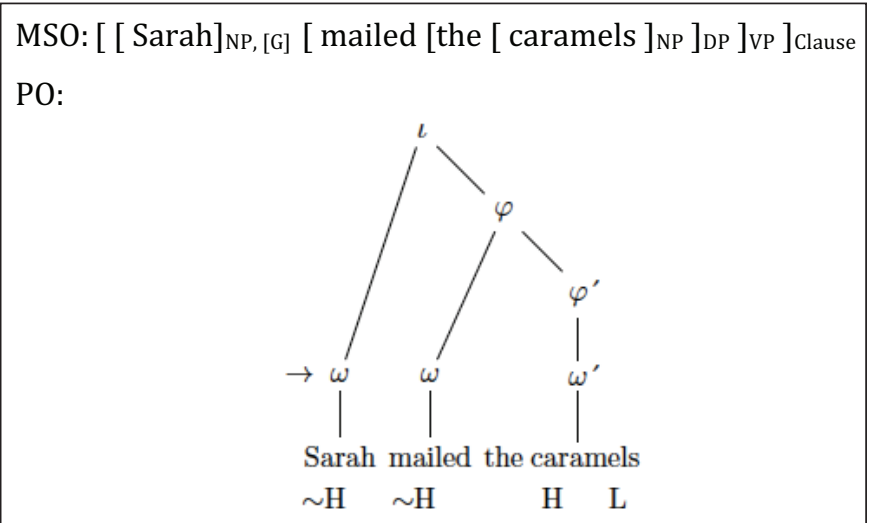

Figure 3: Given subject, otherwise all-new (PO).

\footnotetext{
${ }^{44}$ Since there is no left edge of $\varphi$ preceding the sentence-initial [G]-marked subject, it must be that a markedness constraint analogous to the edge-tone constraint (30) calls for the presence of a tone at the left edge of an intonational phrase 1 .
} 
Our proposal that a [G]-marked phrase of MSO is 'dephrased' in PI predicts the correct prosodic properties of the Given direct object phrase in 39(c) as well. The PO representation of 39(c) is given in Figure 4.

In Figure 4, the absence of the $\mathrm{H}$ accent tone on the Given object phrase caramels reflects the lack of $\varphi$-level head/prominence. Since the direct object does not correspond to a $\varphi$ in PO, the lack of any optional $\sim \mathrm{H}$ accent at the left edge of the direct object is expected, too. The right-edge $\mathrm{L}$ tone present in Figure 4 has typically been analyzed as a clause-level tonal morpheme (Pierrehumbert \& Hirschberg 1991; Bartels 1997).

DephraseGiven also lays the groundwork for explaining the appearance of the obligatory $\mathrm{H}$ accent tone on the VP-initial, merely new, verbal $\omega$ ' sister of the $\omega$ corresponding to the [G]-marked object in the PO in Figure 4. This apparent 'stress shift' to the verb has been much discussed since Ladd (1980). Since the [G]-marked direct object in Figure 4 corresponds to an $\omega$ in PI that is preceded by another $\omega$ (the one corresponding to the verb), the locus of head prominence within the $\varphi$ corresponding to the VP would have to be determined by a 'head assigning' prosodic markedness constraint. The HEAVYSisterPROMINENCE constraint (33) is inapplicable here. A 'head assigning' constraint would come into play when a node in prosodic structure only has same-level daughters. Depending on the language and the level of prosodic constituency at issue, head prominence may then be 'assigned' leftmost or rightmost (Prince 1983; Hayes 1995; Kager 2001; McCarthy 2003). For example, in Standard American and British English, the head prominence of a foot is the leftmost syllable, the head prominence of a $\omega$ is the rightmost foot, the head prominence of a simple compound $\omega$ falls on the leftmost $\omega$. We propose, then, that the apparent 'stress shift' to the verb in VPs with a Given direct object, is the result of a phonological markedness constraint like that in (40) (see McCarthy 2003: 111).

\section{HEAD- $\omega$-LEFTMOST}

The head $\omega$ of a $\varphi$ is not preceded by another $\omega$ within that $\varphi$.

A final issue needs to be addressed in connection with the constraint $[G]=$ no $\varphi$ in (38). Spelling out [G] as absence of $\varphi$ raises an important theoretical issue regarding the interaction of the set of constraints in the mapping from MSO to PI. DephraseGiven is in conflict with MatchPhrase, for example. The inapplicability of MatchPhrase for [G]-marked Phrases in MSO would follow if the constraints governing the mapping from MSO to PI were themselves organized in an optimality theoretic ranking. The spelling out of a [G]-marked Phrase as a mere $\omega$ or sequence of $\omega$ 's in PI would then be the result of the ranking in (41).

$$
[G]=\text { No- } \varphi>>\text { MatchPhrase (Standard American and British English) }
$$

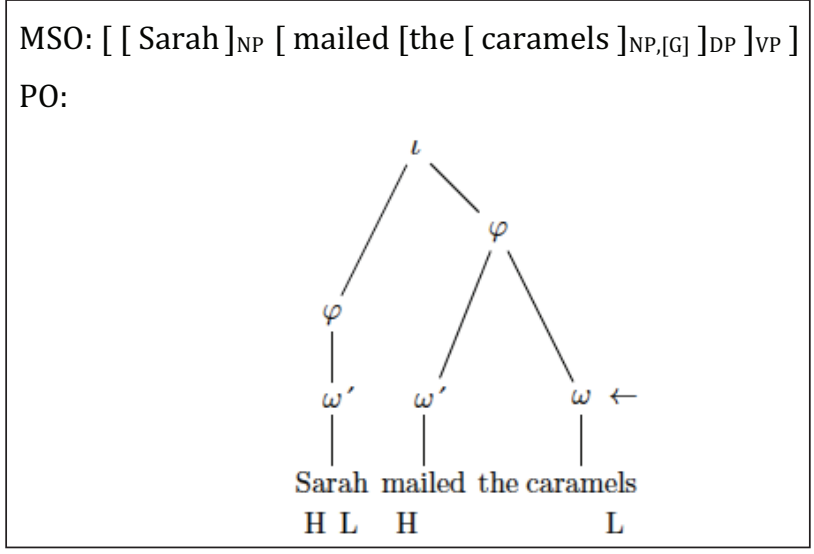

Figure 4: Given object, otherwise all-new (PO). 
An optimality theoretic constraint-ranking-based approach to the MSO-PI interface module of grammar also allows for an account of the phonological properties of [FoC]-marked constituents that are contained within [G]-marked constituents, to be discussed in the next subsection.

\subsection{Second Occurrence FoCus: [FoC]-marking within [G]-marking}

A Second Occurrence FoCus (SOF) is a FoCused constituent contained within a Given constituent. SOF constructions provide a window into the interaction of [FoC] and [G], and are thus ideal testing grounds for our account of the phonology of the two features. The phonological puzzle posed by SOFs is that SOFs do not display the obligatory $\mathrm{H}$ accent tone expected of a $[\mathrm{FoC}]$-marked constituent in Standard American and British English.

The small discourse in (42) illustrates. The example is from Beaver et al. (2007: 256), which experimentally examined the phonological and phonetic properties of SOF sentences. The [FoC]- and [G]-marking in (42) is supplied by us. Beaver et al. experimentally documented the lack of an $\mathrm{H}$ pitch accent for the PO of the SOF Sid in (42) and similar cases.
a. Both Sid and his accomplices should have been named in this morning's court session. But the defendant only named [Síd $]_{\mathrm{FoC}}$ in court today.
b. MSO: Even [the prosecutor $]_{\mathrm{FoC}}\left[\text { only named }[\text { Sid }]_{\mathrm{FoC}} \text { in court today }\right]_{\mathrm{G}}$
c. PI: (Even the (prosecutor $\left.{ }_{\omega}\right) \varphi^{\prime}$ only named $\operatorname{Sid}_{\omega}$ in court $_{\omega}$ today $_{\omega}$ ) $)$
d. PO: (Even the (prosecutor $\left.\omega_{\omega^{\prime}}\right) \varphi^{\prime}$ only named $\operatorname{Sid}_{\omega}$ in court $_{\omega}$ today $_{\omega}$ )

$\mathrm{H} \quad \mathrm{L}$

In 42(a), a prior all-new discourse context is established where the antecedent for the SOF construction in 42(b) appears. Spellout for the [G]-marked constituent in the MSO 42(b) requires that it correspond to a constituent in PI that is not a $\varphi$ and contains no $\varphi$. Such a $\mathrm{PI}$ is given in 42(c). The lack of a $\mathrm{H}$ accent tone for the PO counterpart of the SOF Sid in 42(d) shows that the spellout constraint $[G]=$ No- $\varphi$ is respected in the PI 42(c). So spellout for [G] outranks spellout for $[\mathrm{FoC}]$ in Standard American and British English.

Yet all phonological effects of FoCus are not obliterated in SOF cases. Spellout of [FoC]marking seems to be responsible for the requirement that a SOF contain at least a $\omega$-level prosodic head, namely a head $f^{\prime}$. This requirement can be seen at work in constructions where the SOF is a pronoun. As first observed by San Tunstall and reported in von Fintel (1994), when an SOF is a pronoun, it must appear in its strong form, not in its weak form in English. For him, for example, the weak form is the footless, 'stressless', syllabic nasal $m$. That weak form could not occupy the place of the SOF $[S i d]_{F o C}$ in the MSO 42(b). The strong form him would be required. We conclude that the spellout of [FoC] must be responsible for the realization of SOF pronouns as $\omega$-level heads, that is, with the status of a head foot of a $\omega$. Due to MatchWord, nouns like Sid should have the status of $\omega$, and the sole syllable of Sid would thus be the head of the foot that is the head of that $\omega .{ }^{45}$ It seems, then, that the syntax-phonology interface module of Standard American and British English contains the spellout constraint $[\mathrm{FoC}]=\omega$-Level-Head, in addition to $[\mathrm{FOC}]=\varphi$-Level-Head and $[\mathrm{FoC}]=\imath$-Level-Head we encountered earlier. We have the family of spellout constraints for [FoC] in (43), then.

\footnotetext{
${ }^{45}$ Beaver et al. (2007) did find that the duration and intensity of the SOF word is not identical to that of a merely Given word in the same context. On our account so far, there is no difference in phonological representation that would explain the quite small, though reliable, differences found by Beaver et al. The $\omega$-level-head status of the syllable of the SOF word would not account for their finding, since the Given words with which the SOF properties were compared would have the same prosodic representation. We will come back to this issue in section 8 .
} 


$$
\{[\text { FoC }]=\omega \text {-Level-Head, }[\text { FoC }]=\varphi \text {-Level-Head, }[\text { FoC }]=\imath \text {-Level-Head }\}
$$

This family of constraints is at the basis of the intuitive generalization that, in Standard American and British English, a FoCused constituent has the highest level of prominence it can have, given the demands of other constraints. In our example, the absence of an $\mathrm{H}$ accent tone for the SOF Sid in the PO 42(d) is an indication that the demands of $[\mathrm{FoC}]=\varphi$ Level Head are not respected in the PI 42(c), for example. We have the constraint ranking in (44), then, capturing the intuition that, when it comes to spellout, [G]-marking trumps [FoC]-marking.

$$
[\mathrm{G}]=\text { No- } \varphi>>[\mathrm{FoC}]=\varphi \text {-Level Head (Standard American and British English) }
$$

To conclude this section as a whole, we have shown that the assumption that FoCus and Givenness are represented by syntactically well-motivated features is compatible with an equally well-motivated account of the prosodic effects of FoCus and Givenness in Standard American and British English. As morphosyntactic features, [FoC] and [G] are expected to have phonological impact only at the syntax-phonology interface. We have assumed a modular grammatical architecture where the only possible phonological contribution of [FoC] and [G] could consist in interface constraints for the mapping from morphosyntactic structure to input phonological representation.

We have proposed spellout constraints for $[\mathrm{G}]$ and $[\mathrm{FoC}]$ in Standard American and British English that affect the prosodic constituency of the counterparts of [G]-marked phrases and the prominence level of the counterparts of [FoC]-marked phrases in the input phonological representation. We showed that in interaction with the proposed constraints of the default phonology and their ranking, our proposals for [FoC] and [G] explain well-known and much-discussed observations like the destressing and dephrasing of Given phrases and the lack of a pitch accent for a Second Occurrence FoCus. Most importantly, though, we showed that our account also derives the Katz \& Selkirk facts relating to combinations of FoCus and merely new, which have mostly gone unnoticed or unexplained in the literature.

\section{The meaning and distribution of [FoC] and [G]}

This section will track the effects of [FoC] and [G] at the syntax-semantics/pragmatics interface and show that the two features are responsible for two distinct pressures for marking discourse coherence in Standard American and British English. The existence of two distinct pressures telling discourse participants to signal both matches and contrasts in the ongoing discourse is obscured by the unifying $\mathrm{F}$ (ocus) approaches of Rooth and Schwarzschild, as well as by the various featureless approaches to information structure.

As in section 3, we will rely on the Alternatives Semantics of Rooth (1992a; 2016). Since the discourse requirements triggered by [FoC] and [G] depend on the linguistic and non-linguistic discourse context, we also need some representation of context. We are not assuming any particular representations of discourse contexts here, as long as they provide an updatable record of available discourse referents within a relevant window.

Recall that in Alternatives Semantics, expressions are assigned two semantic values: $\mathrm{O}$-values (ordinary meanings) and A-values (sets of alternatives). The direct contribution of $[\mathrm{FoC}]$ is to introduce alternatives as A-values, as stated in (45).

$$
\begin{aligned}
& \text { The contribution of [FoC] } \\
& \text { O-values: } \\
& \llbracket[\alpha]_{\mathrm{Foc}} \rrbracket_{\mathrm{O}, \mathrm{C}}=\llbracket \alpha \rrbracket_{\mathrm{O}, \mathrm{C}}
\end{aligned}
$$


A-values:

For $\alpha$ of type $\tau$,

$\llbracket[\alpha]_{\mathrm{FoC}} \rrbracket_{\mathrm{A}, \mathrm{C}}=\mathrm{D}_{\tau}$ (the set of all possible entities of type $\tau$ ).

This is standard Roothian Alternatives Semantics: The computation of the O-value of $[\alpha]_{\text {Foc }}$ in a context C overlooks [FoC]-marks and outputs the O-value of $\alpha$ in C. For $\alpha$ of semantic type $\tau$, the A-value of $[\alpha]_{\mathrm{FoC}}$ in $\mathrm{C}$ is the set of all possible entities of type $\tau$.

The [G]-feature places a Givenness requirement on the discourse context, which amounts to establishing an anaphoric relationship with a preceding discourse referent.

\section{(46) Givenness}

An expression $\alpha$ is Given with respect to an individual, property, or proposition $\mathfrak{a}$ in $C$ iff $\llbracket \alpha \rrbracket_{A, C}=\{\mathfrak{a}\}$.

For an expression $\alpha$ to have a chance to be Given with respect to some discourse referent according to (46), it has to have a singleton alternatives set. For this to be possible, it can't contain any [FoC]-marked constituent that has generated alternatives that have not been blocked from propagating ('consumed') by some alternatives-evaluating operator within $\alpha$. This property of Givenness has important consequences for the analysis of Second Occurrence FoCus (SOF), as we will see shortly.

To implement the Givenness requirement attached to [G], we are assuming that, technically, [G] is indexed with a contextually salient discourse referent, a point we have neglected up to now in our representations, and will continue to neglect for convenience when not relevant. We have then:

\section{The contribution of [G]}

O-values

$\mathbb{L}[\alpha]_{G_{a}} \rrbracket_{O, C}$ is defined iff $\mathfrak{a}$ is a discourse referent in the window preceding $C$, and $\alpha$ is Given with respect to $a .{ }^{46}$ If defined, $\llbracket[\alpha]_{G_{a}} \rrbracket_{O, C}=\llbracket \alpha \rrbracket_{O, c}$.

A-values

$\llbracket[\alpha]_{\mathrm{G}_{\mathrm{a}}} \rrbracket_{\mathrm{A}, \mathrm{C}}=\llbracket \alpha \rrbracket_{\mathrm{A}, \mathrm{C}}$.

The [G]-feature introduces a Givenness requirement that has to be satisfied by the utterance context, regardless of how deeply embedded the feature may be. [G] does not contribute anything to the truth-conditional content of the expressions it attaches to, nor does it affect the computation of alternatives. Its contribution is purely use-conditional or expressive in the sense of Kaplan (1999), Kratzer (1999; 2004), Potts (2005), McCready (2010), or Gutzmann (2015; 2019). In that respect, [G] resembles discourse particles like German ja or doch, as suggested in Kratzer (2004). However, [G] also differs from discourse particles and other expressive meanings discussed in the literature in placing a much simpler condition on the discourse context. The appropriateness of [G] does not depend on the mutual beliefs or expectations of discourse participants. All [G] cares about is whether something has been said before or is otherwise contextually salient. We chose to implement the contribution of [G] as a contextual presupposition (Schlenker 2007), but we remain open to the possibility that expressive (use-conditional) meanings are a distinguished class of meanings requiring their own architecture, as argued in Potts (2005) and Gutzmann (2015; 2019).

\footnotetext{
${ }^{46}$ There doesn't seem to be anticipatory licensing of [G]-marking (Rooth 2015) - the antecedent for a [G]marked constituent needs to come from the preceding discourse.
} 
Comparing (45) and (47), a crucial difference between [G] and [FoC] becomes apparent. [G] directly imposes a discourse requirement related to Givenness. [FoC] all by itself does not trigger any discourse requirement, it merely introduces alternatives that can then be used by alternatives-evaluating operators (see Beck 2016 for an overview). Following Rooth (1992a), we are assuming that the contrast requirement that comes with [FoC]marking is introduced by a separate operator $\sim$ (the 'squiggle') marking the scope of the FoCus. The $\sim$ operator can have a detectable presence in syntax. For example, we saw in section 2 that Sinhala has verbal inflection marking the scope of a possibly distant FoCused constituent, suggesting a configuration similar to wh-constructions.

[FoC]-marked constituents must be c-commanded by a $\sim$ operator. ${ }^{47}$ This requirement might be enforced in the syntax via a feature agreement relationship between an interpretable occurrence of $[\mathrm{FoC}]$ that marks the FoCused constituent, and an uninterpretable version of $[\mathrm{FoC}]$ that comes with the $\sim$ operator. ${ }^{48}$ Such an agreement relation is suggested by the Sinhala facts reviewed in section 2 . FoCusing thus always carries a commitment to contrast in the technical sense defined below. A more fleshed-out representation of our earlier dialogue about Sarah vs. Eliza mailing the caramels is (48).

Me: [Sarah mailed the caramels $]_{p}$.

You: (No), $\sim_{p}\left[[\text { Eliza }]_{\mathrm{FoC}}[\text { mailed the caramels }]_{\mathrm{G}}\right]$.

Like [G], the meaning contribution of the $\sim$ operator is expressive (use-conditional). Also like [G], the $\sim$ operator establishes an anaphoric relation to a discourse referent. But with the operator, the relation has to be one of contrast. In our example, the proposition that Sarah mailed the caramels is an obvious propositional antecedent. That proposition is distinct from the proposition that Eliza mailed the caramels and is also among the alternatives determined by the scope of the $\sim$ operator. In this way your reply in (48) represents a contrast with what I said before. (49) defines the notion of contrast representation that we are after.

\section{Contrast representation}

An expression $\alpha$ represents a contrast with a discourse referent (individual, property, proposition) $\mathfrak{a}$ in context $\mathrm{C}$ just in case conditions (i) to (iii) are satisfied:

(i) $\mathfrak{a} \in \llbracket \alpha \rrbracket_{\mathrm{A}, \mathrm{C}^{*}}$

(ii) $\mathfrak{a} \neq \llbracket \alpha \rrbracket_{O, C^{*}}$

(iii) There is no FoC/G-variant $\beta$ of $\alpha$ such that $\llbracket \beta \rrbracket_{\mathrm{A}, \mathrm{C}} \subset \llbracket \alpha \rrbracket_{\mathrm{A}, \mathrm{C}}$ and $\mathfrak{a} \in \llbracket \beta \rrbracket_{\mathrm{A}, \mathrm{C}^{*}}$

Conditions (i) and (ii) say that a contrasting discourse referent for an expression $\alpha$ has to be in the alternatives set for $\alpha$ and it can't have the same meaning (ordinary denotation) as $\alpha .{ }^{49}$ Condition (iii) is there to prevent overFoCusing. Its formulation is adapted from unpublished work by Roger Schwarzschild (Schwarzschild 1993, reported in Truckenbrodt 1995). Without condition (iii), (49) would incorrectly predict that 50(b) below represents a contrast with the proposition expressed by 50(a), for example: The O-values of 50(a) and (b) are different, and the O-value of 50(a) is a member of the A-value of 50 (b). ${ }^{50}$

\footnotetext{
${ }^{47}$ Ultimately, the $\sim$ operator might not be the only operator that can license [FoC]. Constant's topic abstraction operator CT- $\lambda$ (Constant 2012; 2014), for example, should be able to license $[$ FoC], too, since, like the $\sim$ operator, CT- $\lambda$ stops the propagation of alternatives.

${ }^{48}$ We will neglect the presence of uninterpretable $[\mathrm{FoC}]$ on the $\sim$ operator in our representations.

${ }^{49}$ It's controversial whether condition (ii) might be too weak. See e.g. Wagner (2012) vs. Katzir (2013).

${ }^{50} 50$ (b) can be used to contradict 50(a) if strawberries is understood as a contrastive topic, with characteristic, rising, contrastive topic intonation. That's not the contrast relation that we are trying to capture.
} 
(50) a. John picked strawberries at Mary's farm.

b. John picked [strawberries $]_{\mathrm{FoC}}$ at $[\text { Sandy's }]_{\mathrm{FoC}}$ farm.

Schwarzschild (1993: examples 9(a) and (c), using the current notation).

Condition (iii) in (49) disqualifies an expression $\alpha$ from representing a contrast with an entity $\mathfrak{a}$ if a contrast with $\mathfrak{a}$ could also be represented by a FoC/G-variant of $\alpha$ with a smaller alternatives set. Two expressions are FoC/G-variants of each other if they are identical except for [FoC]-marking and [G]-marking. Thanks to condition (iii) in (49), 50(b) does not represent a contrast with the proposition expressed by 50(a): (51) below is a FoC/G variant of 50(a) that has a smaller alternatives set and also represents a contrast with the proposition expressed by 50(a).

$$
\text { John picked strawberries at }[\text { Sandy's }]_{\mathrm{FoC}} \text { farm. }
$$

Some contrasts are trivial. In 52(a) to (c), for example, every word is part of a [FoC]marked constituent and there are no [G]-marked or unmarked (new) parts.

$$
\begin{aligned}
& \text { a. } \left.[\text { Eliza }]_{\mathrm{FoC}}[\text { mailed }]_{\mathrm{FoC}}[\text { the caramels }]_{\mathrm{FoC}}\right] \\
& \text { b. }[\text { Eliza }]_{\mathrm{FoC}}[\text { mailed the caramels }]_{\mathrm{FoC}} \\
& \text { c. }[\text { Eliza mailed the caramels }]_{\mathrm{FoC}}
\end{aligned}
$$

It's too easy for those representations to satisfy the contrast requirement for FoCus, since the alternatives sets generated for such $[\mathrm{FoC}]$-marking configurations are completely unrestricted: they contain any entity whatsoever of the relevant type. Such alternatives sets are trivial in the sense that they coincide with a semantic domain $\mathrm{D}_{\tau}$ for some type $\tau$. Definition (49) doesn't make 52(a) to (c) ineligible for representing contrasts with some discourse antecedent. We think that this is right, since examples like 52(a), for example, might easily be uttered by a grade school teacher giving dictation. However, as we will discuss shortly, there is pressure in Standard American and British English to represent contrasts with discourse referents from the preceding context. That pressure does not seem to extend to trivial contrasts. While there is nothing ungrammatical about representing trivial contrasts on our account, then, there is no pragmatic pressure to do so.

With a workable condition for contrast representation in place, a meaning definition for the operator can be stated as in (53).

$$
\begin{aligned}
& \text { The } \sim \text { operator } \\
& \text { O-values } \\
& \llbracket \sim_{a} \alpha \rrbracket_{O, C} \text { is only defined, if } a \text { is a discourse referent in the discourse window sur- } \\
& \text { rounding } C \text {, and } \alpha \text { represents a contrast with } a \text {. If defined, } \llbracket \sim_{a} \alpha \rrbracket_{O, C}=\llbracket \alpha \rrbracket_{O, C^{*}} \\
& \text { A-values } \\
& \llbracket \sim_{a} \alpha \rrbracket_{A, C}=\left\{\llbracket \alpha \rrbracket_{O, C}\right\} .
\end{aligned}
$$

Rather than merely representing a contrast with a single discourse antecedent $\mathfrak{a}$, as assumed in (53), an expression $\alpha$ might also represent a contrast with each member of a set of contextually salient discourse antecedents $\mathfrak{c}$. A relevant example was the Katz \& Selkirk example from section 4. There, we were told about an art dealer, Gary, who doesn't do business with the Guggenheim or the Metropolitan, but would only offer his Modigliani painting to MoMa. In this mini-discourse, the proposition that Gary would offer his Modigliani to MoMa is contrasted with two contextually salient propositions, namely that he would offer the painting to the Guggenheim, and that he would offer it to the Metropolitan. To allow for multiple contrasting antecedents, we could adopt (54) instead of (53). 


\section{The $\sim$ operator (allowing multiple antecedents)}

O-values

$\llbracket \sim_{\mathfrak{C}} \alpha \rrbracket_{O, C}$ is only defined, if $\mathfrak{C}$ is a set of discourse referents in the discourse window surrounding $\mathrm{C}$, and $\alpha$ represents a contrast with each member of $\mathfrak{c}$. If defined,

$\llbracket \sim_{\mathbb{C}} \alpha \rrbracket_{O, C}=\llbracket \alpha \rrbracket_{O, C}$.

A-values

$\llbracket \sim_{\mathfrak{C}} \alpha \rrbracket_{\mathrm{A}, \mathrm{C}}=\left\{\llbracket \alpha \rrbracket_{\mathrm{O}, \mathrm{C}}\right\}$.

While (54) allows multiple contrastive antecedents, it differs crucially from Rooth (1992a) and Schwarzschild (1999) in having no provision for questions as possible antecedents. As we saw in section 4, questions do not have a special, direct, relation to FoCus. While constituent questions denote sets of propositional alternatives (Hamblin 1973), they do not automatically make those alternatives available as contrasting discourse antecedents without additional contextual support. Unlike Rooth's operator, ours has the effect that [FoC]-marked constituents always signal a contrast.

With Rooth (1992a), (53) and (54) assume that the $\sim$ operator stops the propagation of alternatives and thereby blocks access to those alternatives for higher operators. ${ }^{51}$ Association with FoCus-sensitive operators like only or even is then indirect on Rooth's account, and is mediated via two occurrences of a contextual variable (our ()), as illustrated in 55(b), which presents the essential pieces of the logical form of 55(a).

a. Only Amanda passed the bar exam.

b. Only ${ }_{\mathfrak{C}}\left[\sim_{\mathfrak{E}}[\text { Amanda }]_{\mathrm{FoC}}\right.$ passed the bar exam $]$.

A simplified version of the semantics of only could now look as follows.

$$
\begin{aligned}
& \text { The semantics of only (good enough for now) } \\
& \text { O-values } \\
& \llbracket \text { only } \mathbb{E}_{\mathrm{O}, \mathrm{C}}=\lambda \mathrm{p} \lambda \mathrm{w} \forall \mathrm{q}((\mathrm{q} \in \mathbb{C} \& \mathrm{q}(\mathrm{w})) \rightarrow \mathrm{q}=\mathrm{p}) \\
& \text { A-values } \\
& \llbracket \text { only }_{\mathbb{C}} \rrbracket_{\mathrm{A}, \mathrm{C}}=\left\{\llbracket \text { only }_{\mathbb{C}} \mathbb{D}_{\mathrm{O}, \mathrm{C}}\right\} .
\end{aligned}
$$

The semantics for only in (56) has the effect that for a sentence like 55(a) to be true, Amanda has to have passed the bar exam and all other propositions in a contextually salient set of propositions $\mathfrak{C}$ have to be false. Since there is a second instance of $\mathfrak{C}$ that comes with the $\sim$ operator adjacent to only (as shown in 55(b)), each proposition in $\mathbb{c}$ has to be in the alternatives set 57(b) for 57(a). In this way, only indirectly associates with a FoCus in its scope.

a. $[\text { Amanda }]_{\mathrm{FoC}}$ passed the bar exam.

b. AAmanda passed the bar exam, Noah passed the bar exam, Eliza passed the bar exam, Leif passed the bar exam ....

On our account, all the $\sim$ operator itself contributes to the interpretation of 55(a), formalized as 55(b), is an expressive meaning component, that is, a requirement for contrast with one or more salient discourse referents. In this particular example, the contrasting

\footnotetext{
${ }^{51}$ Bade \& Sachs (2019) argue that not all operators that evaluate alternatives stop the propagation of alternatives. If they did, they would all trigger intervention effects, which is not the case. We are setting this issue aside here, even though Bade \& Sachs's observations may have consequences for our account of Second Occurrence FoCus that still need to be looked into.
} 
discourse referents might be contextually salient propositions about other candidates who might or might not have passed the bar exam. In contexts where it's not mutually known who those other candidates were, Amanda could simply be contrasted with the 'nonAmandas', whoever they may be. In the place of only in 55(a) and (b), we might also have a silent exhaustivity operator of the kind identified for Hungarian (Szabolcsi 1981; É. Kiss 1998; Horvath 2010). In either case, the exhaustivity operator indirectly associates with [FoC] via the $\sim$ operator, which contributes an expressive meaning component signaling a contrast.

Our assumptions about [FoC] and [G] have consequences for their interaction. As syntactic features, $[\mathrm{FoC}]$ and $[\mathrm{G}]$ are associated with syntactic nodes and are technically part of their labeling. What would happen, then, if a single constituent $\alpha$ was associated with both $[\mathrm{FoC}]$ and $[\mathrm{G}]$ ? We are assuming, as is common for cases where a single constituent is associated with multiple syntactic features, ${ }^{52}$ that $\alpha$ would then have to conjunctively satisfy the conditions imposed by each feature. With [FoC] and [G], this would create a problem for the computation of A-values. The condition for [G] implies that the A-value of $\alpha$ needs to be a singleton set, but the condition for [FoC] wants it to be the semantic domain $\mathrm{D}_{\tau}$, for $\alpha$ of type $\tau$. Assuming that no semantic domain is a singleton set, an expression cannot satisfy both of those conditions. It follows that no constituents can be both [G]-marked and [FoC]-marked.

More generally, our account of [G] and [FoC] implies that a constituent $\alpha$ that contains a FoCus can be Given only if it also contains an operator that consumes the alternatives generated by that FoCus. Otherwise $\alpha$ wouldn't have a singleton alternatives set, hence couldn't be Given. We have the generalization in (58), then.

\section{The interaction of [G] and [FoC] (derivable)}

A constituent $\alpha$ containing a [FoC]-marked constituent $\beta$ can be [G]-marked only if it also contains an operator that consumes the alternatives generated by $\beta$.

If the $\sim$ operator, which obligatorily comes with only, stops the propagation of alternatives, we have an explanation for the otherwise puzzling distribution of pitch accents in Second Occurrence FoCus (SOF) examples like (64) from Büring (2015a).

Our grad students only quote the faculty. - No, the fáculty only quote the faculty. Büring (2015a: 74).

The second part of this exchange has two instances of the DP the faculty, which already occurred in the first sentence. Both repeated instances of the faculty are FoCused. FoCus on the first one contributes to representing a contrast with the previously mentioned proposition that our grad students only quote the faculty. That FoCus shows the expected prosodic effects of FoCus. FoCus on the second repeated instance of the faculty is there because of its association with only. That instance of a FoCus has the reduced prosody of SOF. Within our framework of assumptions, (59) would be represented as (60), neglecting the anaphoric index for [G].

[Our grad students only quote the faculty $]_{p}$. - No

$\left.\sim_{\mathfrak{p}}[\text { TThe faculty }]_{\mathrm{FoC}}\left[\text { only } \sim_{\mathfrak{a}}\left[\text { quote }[\text { the faculty }]_{\mathrm{FoC}}\right]\right]_{\mathrm{G}}\right]$.

The first instance of the faculty in (60) is [FoC]-marked to convey the intended contrastive interpretation. But then it can't also be [G]-marked. This instance of the faculty is

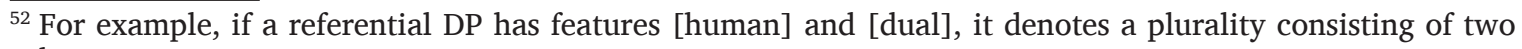
humans.
} 
thus expected to show the prosodic effects of FoCus. It has a pitch accent. The second occurrence of the faculty in (60), on the other hand, is a [FoC]-marked phrase contained within a VP that is headed by only next to a $\sim$ operator. ${ }^{53}$ The $\sim$ operator consumes the alternatives generated in its scope, and only isn't FoCused, hence doesn't introduce any alternatives of its own. As a consequence, the VP headed by only has a singleton alternatives set. Since the VP also has a match in the previous discourse, it can be [G]-marked. The second occurrence of the faculty in (60) is thus expected to show the prosodic effects of SOF. It has no pitch accent. However, to complete our account of SOF, we still need to reckon with the finding of Beaver et al. (2007) that the duration and intensity of an SOF word is not identical to that of a merely Given word, an issue we had to leave open in the previous section. Since an SOF word is [FoC]-marked, hence is not Given and thus cannot be [G]-marked, we could account for the difference between SOF words and Given words by positing an additional spellout constraint saying that a [G]-marked word cannot be an $\omega .{ }^{54}$ The difference between SOF words and Given words would then be that an SOF word has to be an $\omega$, while a Given word can't be.

We can now see that the simple and intuitive idea of a Second Occurrence FoCus as a FoCus contained within a Given constituent, as proposed in Selkirk (2008), is viable, contrary to the assessment of Büring (2015a). The facts can be accounted for by natural assumptions about FoCus, Givenness, and the propagation and consumption of alternatives within Alternatives Semantics.

Our analysis of (60) is not complete yet, though. There are still issues we need to attend to. In the mini-discourse (60), both instances of the faculty are intuitively given. Yet both are [FoC]-marked in (60), which prevents them from being [G]-marked, as we have seen. Is this [FoC]-marking legitimate? Isn't there pressure for [G]-marking intuitively given constituents in Standard American and British English? If there is, why does that pressure not show up in examples like (60)? It turns out that [FoC]-marking can legitimately preempt [G]-marking, assuming that [G]-marking is guided by a principle like (61).

\section{Pressure for [G] -Marking 55}

[G]-mark a constituent if it is Given with respect to a salient discourse referent in the preceding discourse.

Before continuing, we should note, that for ease of display, we have been neglecting, and will continue to neglect, predictable nesting of [G]-marking in our representations. This should not be understood as meaning that, technically, there is no nested [G]-marking. Assuming this notational shortcut, there is no constituent in (60) that is Given, but not [G]-marked. Since both occurrences of the faculty in (60) are [FoC]-marked, they are not Given in the technical sense of definition (46), which requires a singleton alternatives set. (60) doesn't violate Pressure for [G]-Marking, then. [FoC]-marking can indeed preempt [G]-marking.

We are not out of the woods with example (60), though. [FoC]-marking of the first instance of the faculty isn't a mere option in (60). It is obligatory. Why is that? It looks like there isn't only pressure for [G]-marking, there is also pressure for [FoC]-marking. To probe into this pressure, we will look at an example of the kind discussed in Williams

\footnotetext{
${ }^{53}$ Note that the embedded $\sim_{a}$ operator has no linguistic antecedent. We have to accommodate a contrasting discourse referent, then, like the property of quoting the people who are not members of the faculty, for example.

${ }^{54}$ The prosodic structure representations Figure 3 and Figure 4 in section 7 would have to be adjusted accordingly.

${ }_{55}$ The formulation in (61) glosses over the fact that only Words or Phrases of MSO can be [G]-marked. In this respect, [G]-marking differs from [FoC]-marking (Artstein 2004).
} 
(1997). Williams (1997) discusses cases where constituents that might intuitively seem to be Given are nevertheless obligatorily FoCused. (62) illustrates with an example that is a variation of one by Williams.

(62) Me: Roman doubted that it would be hot and predicted that it would be cold. \#You: $[\text { Máx }]_{\mathrm{FoC}}[\text { doubted }]_{\mathrm{G}}[\text { that it would be cold }]_{\mathrm{G}}$.

Your reply in (62) is deviant in the given context, and severely so. According to Williams (1997: 599), the problem with cases like (62) is that "cumulative destressing is not allowed. One cannot destress one phrase and then destress its neighbor, with separate licensing of each." Williams (1997; 2012), Schwarzschild (1999), and Wagner (2005; 2012) have accounts that, each in their own way, converge on Williams' diagnosis of what is wrong with cases like (62). Rephrasing the diagnosis in our own words, there appears to be a problem when two sister constituents $\alpha$ and $\beta$ lack prominence without their mother constituent $\alpha \beta$ being Given. In your reply in (62), both doubted and that it would be cold lack prominence, but doubted that it would be cold as a whole is not Given.

Williams' diagnosis doesn't seem quite right yet. 63(a) and (b) go against it. ${ }^{56}$

(63) a. Sally ran into Max before getting money from the ATM. She ended up lénding $\left.\left[\mathrm{Max}_{\mathrm{G}} \text { [some of the money }\right]_{\mathrm{G}}\right] .{ }^{57}$

b. The Borsalino shop is having an amazing sale on hats. But Max's partner

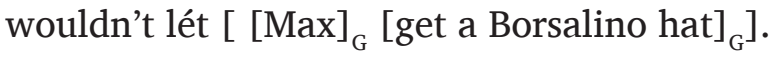

63(a) and (b) are acceptable without prominence on any of the Given constituents, even though Max's getting some of Sally's money or the possibility of his getting a Borsalino hat are not understood to be contextually implied by the respective stretches of preceding discourse. But then 63(a) and (b) have configurations where two sister constituents lack prominence without their mother constituent being Given. What, then, is the difference between the deviant example (62) on the one hand, and the acceptable 63(a) and (b) on the other?

Our assessment of the deviance of your reply in (62) is that in Standard American and British English, there is pressure for representing non-trivial contrasts with salient discourse referents from the preceding discourse. ${ }^{58}(62)$ is deviant because opportunities for representing non-trivial contrasts have been overlooked. There were two such opportunities, those in (64) and (65).

(64) Me: Roman doubted that it would be hot and [(he) predicted that it would be cold $]_{\mathrm{p}}$.

You: $\sim_{\mathfrak{p}}\left[\mathrm{MMáx}_{\mathrm{FoC}}[\text { dóubted }]_{\mathrm{FoC}}[\text { that it would be cold }]_{\mathrm{G}}\right]$.

(65) Me: [Roman doubted that it would be hot $]_{\mathfrak{p}}$ and predicted that it would be cold.

You: $\sim_{\mathfrak{p}}\left[[\mathrm{Máx}]_{\mathrm{FoC}}[\text { doubted }]_{\mathrm{G}}\right.$ that it would be $\left.[\text { cóld }]_{\mathrm{FoC}}\right]$.

\footnotetext{
$\overline{{ }^{56} \text { Williams would }}$ rule out 67 (a) and (b) as violations of his Disanaphora Law. For Schwarzschild, his Givenness requirement would be violated, and for Wagner his Relative Givenness requirement. Williams, Schwarzschild, and Wagner would all wrongly rule out 67(a) and (b), then.

${ }^{57}$ We are assuming that [Max some of the money] is a constituent in 63(a). This is compatible with Harley (1995; 2002) and other analyses of double object constructions. With Green (1974) and Harley, we assume further that the double object configuration here includes a silent HAVE, so that we have a constituent [Max [HAVE some of the money]].

${ }^{58}$ While English allows contrasts to be represented with discourse referents in the subsequent context, there doesn't seem to be pressure to do so.
} 
63(a) and (b) were constructed so as to not provide opportunities for representing (nontrivial) contrasts with salient discourse referents from the preceding context. Without those opportunities, the pressure for representing contrasts seems off. We propose the principle in (66), which forces [FoC]-marking when there are opportunities for representing non-trivial contrasts.

\section{Pressure for [FoC] -Marking}

Represent non-trivial contrasts with salient discourse referents in the preceding discourse.

(66) is a very different kind of principle from (61). (66) faults an expression if it could have represented a (non-trivial) contrast with a salient discourse referent, but missed the opportunity. Unlike (61), (66) requires us to check relevant FoC/G variants of expressions when evaluating them for compliance. Not [FoC]-marking the faculty in (60) would violate (66), since there would be a FoC/G variant (the representation actually given in (60)) that represents a contrast with a salient discourse referent in the preceding discourse. (66) thus forces [FoC]-marking of the faculty in (60), and thereby preempts [G]-marking. Likewise, (62) violates (66) because of the existence of (64) and (65). In (64), Pressure for [FoC]-Marking preempts [G]-marking of doubted, and in (65), it preempts [G]-marking of cold.

An important question which we will have to leave for more detailed corpus and experimental investigations is what happens when there are several opportunities for representing non-trivial contrasts that couldn't all be realized simultaneously. (64) vs. (65) present a situation of this kind. In this case, there are two mutually incompatible ways of representing a contrast with the previous discourse, and both options are equally acceptable. But might there also be cases where there is a ranking, as Truckenbrodt (1995) has suggested? We don't know (yet).

A more fundamental question that is now on the table is why there are such principles as Pressure for [FoC]-Marking and Pressure for [G]-Marking to begin with. What is it that makes [G]-marking and [FoC]-marking obligatory under certain discourse conditions in American and British English? It is tempting to hold Heim's (1991) Maximize Presuppositions principle responsible, as proposed in Wagner (2005; 2012). As Heim was well aware, though, such a principle would need to be formulated very carefully. In our case, we would have to explain, for example, why discourse particles like German ja and doch, which only have expressive meanings, too, are not obligatory, even when the presuppositions they place on the discourse context are mutually known to be satisfied. Why should presence vs. absence of [G]-marking or [FoC]-marking be decided by Maximize Presuppositions, while presence vs. absence of a discourse particle would not be? The answer to this question requires an answer to the more general question of what it is that makes two or more expressions competitors with respect to Maximize Presuppositions. This last question is rarely addressed in the extant literature. We thus do not (yet) have a complete answer to the question of what makes [G]-marking and [FoC]-marking obligatory in Standard American and British English.

To conclude, this section has laid out the syntactic, semantic, and pragmatic properties of the features $[\mathrm{FoC}]$ and $[\mathrm{G}]$. The two features are quite different from each other, but both fall into familiar categories. [FoC] resembles the $[w h]$-feature in that it introduces alternatives. Also like [wh], [FoC] comes with an obligatory operator, and it's technically that operator that is responsible for its meaning contribution. Both [FoC] and [G] contribute expressive (use-conditional) meanings. [G] signals a match in the preceding discourse, $[\mathrm{FoC}]$ points to a contrast. Unlike [FoC], though, [G] contributes its meaning directly, rather than with the help of an operator. 
We already saw in section 7 that Second Occurrence FoCus offers an ideal window into the combined effects of $[\mathrm{FoC}]$ and $[\mathrm{G}]$ in the phonology. Second Occurrence FoCus is equally revealing for the interaction of $[\mathrm{FoC}]$ and $[\mathrm{G}]$ in the semantics. Characterizing the semantic properties of [FoC] and [G] within Alternatives Semantics made it possible for us to maintain the simple generalization of Selkirk (2008): The characteristic reduced prosody of a Second Occurrence FoCus results when a FoCused constituent is contained within a Given constituent.

Apart from a new analysis of Second Occurrence FoCus, a major finding of this section and this paper as a whole is that [FoC] and [G] generate two distinct obligatory prosodic strategies for achieving discourse coherence in Standard American and British English. The existence of two interacting prosodic strategies, with one preempting the other, is bound to be of interest for theories of speech production and processing. The prosody of speakers of Standard American and British English does not only have to reflect the presence of matching discourse referents, it also has to signal (and is allowed to anticipate) the presence of contrasting discourse referents. Our finding thus opens up a rich new agenda for experimental and corpus investigations of how discourse participants establish, recognize, and exploit discourse anaphoric relationships.

\section{Conclusion}

Dichotomies like the given-new or the focus-background distinctions are at the very core of research on information structure. We have made a case that the many diverse syntactic, semantic, pragmatic, and phonological effects of those dichotomies can be traced back to the impact of two syntactically motivated privative features [FoC] and [G]. There is nothing special about the semantics of [FoC] and [G]. Both contribute simple expressive meanings, signaling contrasts or matches in the ongoing discourse. There is also nothing special about the phonology of [FoC] and [G]. Both happen to be spelled out prosodically in Standard American and British English. As interface features, [FoC] and [G] interact with the semantics and pragmatics and leave reflexes in the phonology, creating an astonishing range of phenomena that have been thought to constitute a field of study of its own, governed by its own principles. That was all wrong. There is no such thing as information structure that deserves this name.

\section{Acknowledgements}

This article is dedicated to the memory of Michael Rochemont.

We are very grateful to three anonymous reviewers and the editor of Glossa, who went far beyond the call of duty to help us bring this many-year project to a conclusion. We are also very grateful to the audiences of the classes we have taught and the many talks we have given on the topic over the last decade or more.

\section{Funding Information}

This work was supported by NSF grants 0004038 and 1147083 to Elisabeth Selkirk and by a Radcliffe Fellowship and a Leverhulme Visiting Professorship at University College London for Angelika Kratzer.

\section{Competing Interests}

The authors have no competing interests to declare.

\section{References}

Aboh, Enoch O. 2007a. Focused versus non-focused wh-phrases. In Katharina Hartmann \& Malte Zimmermann (eds.), Focus strategies in African languages: The interaction of focus and grammar in Niger-Congo and Afro-Asiatic, 287-314. Berlin: De Gruyter Mouton. DOI: https://doi.org/10.1515/9783110199093 
Aboh, Enoch O. 2007b. Leftward focus versus rightward focus: The Kwa-Bantu conspiracy. SOAS Working Papers in Linguistics 15. 81-104.

Aboh, Enoch O. 2010. Information structure begins with the numeration. Iberia: An International Journal of Theoretical Linguistics 2. 12-42.

Aboh, Enoch O. 2016. Information structure: A cartographic perspective. In Caroline Féry \& Shinichiro Ishihara (eds.), The Oxford handbook of information structure, 147-164. Oxford: Oxford University Press. DOI: https://doi.org/10.1093/ oxfordhb/9780199642670.013.004

Agbayani, Brian \& Chris Golston. 2010. Phonological movement in Classical Greek. Language 86. 133-167. https://www.jstor.org/stable/40666301. DOI: https://doi. org/10.1353/lan.0.0186

Agbayani, Brian \& Chris Golston. 2016. Phonological constituents and their movement in Latin. Phonology 33. 1 - 42. DOI: https://doi.org/10.1017/S0952675716000026

Aldridge, Edith. 2018. C-T inheritance and the left periphery in Old Japanese. Glossa 3(1). 26. DOI: https://doi.org/10.5334/gjgl.254

Ameka, Felix K. 2010. Information packaging constructions in Kwa: Microvariation and typology. In Enoch O. Aboh \& James Essegbey (eds.), Topics in Kwa syntax, 141-176. Dordrecht: Springer. DOI: https://doi.org/10.1007/978-90-481-3189-1_7

Arregi, Karlos. 2016. Focus projection theories. In Caroline Féry \& Shinichiro Ishihara (eds.), The Oxford handbook of information structure, 185-202. Oxford: Oxford University Press. DOI: https://doi.org/10.1093/oxfordhb/9780199642670.013.005

Artstein, Ron. 2004. Focus below the word level. Natural Language Semantics 12. 1-22. https://www.jstor.org/stable/23749600. DOI: https://doi.org/10.1023/ B:NALS.0000011145.76954.0b

Bade, Nadine \& Konstantin Sachs. 2019. EXH passes on alternatives: A comment on Fox and Spector (2018). Natural Language Semantics 27. 19-45. DOI: https://doi. org/10.1007/s11050-019-9149-7

Barnes, Jonathan, Nanette Veilleux, Alejna Brugos \& Stephanie Shattuck-Hufnagel. 2010. Turning points, tonal targets, and the English L-phrase accent. Language, Cognition and Neuroscience 25. 982-1023. DOI: https://doi.org/10.1080/016909610035 99954

Bartels, Christine. 1999. The intonation of English statements and questions: A compositional interpretation. New York: Garland Publishing.

Beaver, David, Brady Clark, Edward Stanton Flemming, T. Florian Jaeger \& Maria Wolters. 2007. When semantics meets phonetics: Acoustical studies of Second-Occurrence Focus. Language 83. 245 - 276. DOI: https://doi.org/10.1353/lan.2007.0053

Beaver, David \& Dan Velleman. 2011. The communicative significance of primary and secondary accents. Lingua 121. 1671-1692. DOI: https://doi.org/10.1016/j.lingua.2011.04.004

Beck, Sigrid. 2006. Intervention effects follow from focus interpretation. Natural Language Semantics 14. 1 -56. DOI: https://doi.org/10.1007/s11050-005-4532-y

Beck, Sigrid. 2016. Focus sensitive operators. In Caroline Féry \& Shinichiro Ishihara (eds.), The Oxford handbook of information structure, 227-250. Oxford: Oxford University Press.

Beckman, Mary E. 1982. Segment duration and the 'mora' in Japanese. Phonetica 39. 113 - 135. DOI: https://doi.org/10.1121/1.386081

Beckman, Mary E. 1986. Stress and non-stress accent (Netherlands Phonetic Archives 7). Dordrecht: Foris. DOI: https://doi.org/10.1515/9783110874020

Beckman, Mary E. \& Janet B. Pierrehumbert. 1986. Intonational structure in Japanese and English. Phonology Yearbook 3. 255-309. DOI: https://doi.org/10.1017/ S095267570000066X 
Belletti, Adriana. 2001. Inversion as focalization. In Aafke C. J. Hulk \& Jean-Ives Pollock (eds.), Subject inversion in Romance and the theory of Universal Grammar, 60-90. Oxford: Oxford University Press.

Belletti, Adriana. 2004. Aspects of the low IP area. In Luigi Rizzi (ed.), The structure of CP and IP. The cartography of syntactic structures, vol. 2, 16-51. Oxford: Oxford University Press.

Bennett, Ryan \& Emily Elfner. 2019. The syntax-prosody interface. Annual Review of Linguistics 5. 151-171. DOI: https://doi.org/10.1146/annurev-linguistics-011718-012503

Bennett, Ryan, Emily Elfner \& James McCloskey. 2016. Lightest to the right: An apparently anomalous displacement in Irish. Linguistic Inquiry 47. 169-234. DOI: https:// doi.org/10.1162/LING_a_00209

Bianchi, Valentina. 2013. On Focus Movement in Italian. In Victoria Camacho-Taboada, Ángel L. Jiménez-Fernández, Javier Martín-González \& Mariano Reyes-Tejedor (eds.), Information structure and agreement, 193-216. Amsterdam: John Benjamins. DOI: https://doi.org/10.1075/la.197.001int

Bianchi, Valentina, Giuliano Bocci \& Silvio Cruschina. 2016. Focus fronting, unexpectedness, and evaluative implicatures. Semantics \& Pragmatics 9. 3. 1-54. DOI: https://doi. org/10.3765/sp.9.3

Bocci, Guiliano. 2013. The syntax-prosody interface from a cartographic perspective: Evidence from Italian. Amsterdam: John Benjamins Publishing Company. DOI: https://doi. org/10.1075/la.204

Bolinger, Dwight. 1965. Pitch accent and sentence rhythm. In Isamu Abe \& Tetsuya Kanekiyo (eds), Forms of English: Accent, morpheme, order, 139-180. Tokyo: Hokuou.

Bresnan, Joan. 1971. Sentence stress and syntactic transformations. Language 47. 257 - 281. https://www.jstor.org/stable/412081. DOI: https://doi.org/10.2307/412081

Büring, Daniel. 2003. On D-trees, beans, and B-accents. Linguistics and Philosophy 26. 511-545. DOI: https://doi.org/10.1023/A:1025887707652

Büring, Daniel. 2015a. A theory of Second Occurrence Focus. Language, Cognition, and Neuroscience 30. 73-87. DOI: https://doi.org/10.1080/01690965.2013.835433

Büring, Daniel. 2015b. Unalternative Semantics. Semantics and Linguistic Theory (SALT) 25. 550-575. DOI: https://doi.org/10.3765/salt.v25i0.3634

Büring, Daniel. 2016. Intonation and meaning. Oxford: Oxford University Press. DOI: https://doi.org/10.1093/acprof:oso/9780199226269.001.0001

Calhoun, Sasha. 2010. The centrality of metrical structure in signaling information structure: A probabilistic perspective. Language 86. 1-42. https://www.jstor.org/stable/40666298. DOI: https://doi.org/10.1353/lan.0.0197

Chafe, Wallace L. 1976. Givenness, contrastiveness, definiteness, subjects, topics and point of view. In Charles N. Li (ed.), Subject and topic, 27-55. New York: Academic Press.

Chomsky, Noam. 1971. Deep Structure, Surface Structure, and semantic interpretation. In Danny D. Steinberg \& Leon A. Jakobovits (eds.), Semantics. An interdisciplinary reader in Philosophy, Linguistics and Psychology, 183-216. Cambridge: Cambridge University Press.

Chomsky, Noam \& Morris Halle. 1968. The sound pattern of English. Cambridge, MA: The MIT Press.

Cinque, Guglielmo. 1993. A null theory of phrase and compound stress. Linguistic Inquiry 24. 239-297. https://www.jstor.org/stable/4178812

Constant, Noah. 2012. Topic abstraction as the source for nested alternatives. A conservative semantics for contrastive topic. West Coast Conference on Formal Linguistics (WCCFL) 30, 120-130. Somerville: Cascadilla Proceedings Project. 
Constant, Noah. 2014. Contrastive topic: Meanings and realizations. Amherst, MA: University of Massachusetts dissertation. https://scholarworks.umass.edu/dissertations_2/171

Corbett, Greville. 2012. Canonical morphosyntactic features. In Dunstan Brown, Marina Chumakina \& Greville G. Corbett (eds.), Canonical morphology and syntax, 48-65. Oxford: Oxford University Press. DOI: https://doi.org/10.1093/acprof: oso/9780199604326.003.0003

D'Imperio, Mariapaola. 1997. Breadth of focus, modality, and prominence perception in Neapolitan Italian. OSU Working Papers in Linguistics 50. 19-39.

de Lacy, Paul. 2002. The interaction of tone and stress in Optimality Theory. Phonology 19. 1-32. DOI: https://doi.org/10.1017/S0952675702004220

Delfitto, Denis \& Gaetano Fiorin. 2015. Exhaustivity operators and fronted focus in Italian. In Elisa Di Domenico, Cornelia Hamann \& Simona Matteini (eds.), Structures, strategies and beyond. Studies in honor of Adriana Belletti, 163-180. Amsterdam: John Benjamins. DOI: https://doi.org/10.1075/la.223.08del

É. Kiss, Katalin. 1998. Identificational focus versus information focus. Language 74. 245-273. https://www.jstor.org/stable/417867. DOI: https://doi.org/10.1353/ lan.1998.0211

Elfner, Emily. 2012. Syntax-prosody interactions in Irish. Amherst, MA: University of Massachusetts dissertation. DOI: https://doi.org/10.7275/3545-6n54

Elfner, Emily. 2015. Recursion in prosodic phrasing: Evidence from Connemara Irish. Natural Language and Linguistic Theory 33. 1169-1208. DOI: https://doi.org/10.1007/ s11049-014-9281-5

Elordieta, Gorka \& Elisabeth Selkirk. 2018. Notes on prosodic headedness and tone in Tokyo Japanese, Standard English and Northern Bizkaian Basque. In Hana-bana: A Festschrift for Junko Ito and Armin Mester. Santa Cruz, CA: UC Santa Cruz Linguistics Research Center. http://itomestercelebration.sites.ucsc.edu/.

Embick, David \& Rolf Noyer. 2007. Distributed Morphology and the syntax/morphology interface. In Gillian Ramchand \& Charles Reiss (eds.), The Oxford handbook of linguistic interfaces, 289-324. Oxford: Oxford University Press. DOI: https://doi.org/10.1093/ oxfordhb/9780199247455.013.0010

Féry, Caroline. 2017. Intonation and Prosodic Structure. Cambridge: Cambridge University Press. DOI: https://doi.org/10.1017/9781139022064

Féry, Caroline \& Vieri Samek-Lodovici. 2006. Focus projection and prosodic prominence in nested foci. Language 82. 131-150. https://www.jstor.org/stable/4490087. DOI: https://doi.org/10.1353/lan.2006.0031

Fiedler, Ines \& Stefanie Jannedy. 2013. Prosody and focus marking in Ewe. Journal of African Languages and Linguistics 34. 1-46. DOI: https://doi.org/10.1515/jall-2013-0001

Fox, Danny \& Benjamin Spector. 2018. Economy and embedded exhaustification. Natural Language Semantics 26. 1-50. DOI: https://doi.org/10.1007/s11050-017-9139-6

Frota, Sonia. 2000. Prosody and focus in European Portuguese: Phonological phrasing and intonation. New York: Garland Publishing.

Green, Georgia. 1974. Semantics and syntactic regularity. Bloomington, IN: Indiana University Press.

Green, Melanie \& Philip Jaggar. 2003. Ex-situ and in-situ focus in Hausa: Syntax, semantics, and discourse. Research in Afroasiatic Grammar 2. 187-213. DOI: https:// doi.org/10.1075/cilt.241.11gre

Gribanova, Vera \& Stephanie Shih. 2016. The morphosyntax-phonology connection: Locality and directionality at the interface. Oxford: Oxford University Press. DOI: https://doi. org/10.1093/acprof:oso/9780190210304.001.0001 
Grice, Martine, D. Robert Ladd \& Amalia Arvaniti. 2000. On the place of phrase accents in intonational phonology. Phonology 17. 143-185. DOI: https://doi.org/10.1017/ S0952675700003924

Gundel, Jeanette. 1988. Universals of topic-comment structure. In Michael Hammond, Edith A. Moravcsik \& Jessica Wirth (eds.), Studies in Syntactic Typology, 209-299. Amsterdam: John Benjamins. DOI: https://doi.org/10.1075/tsl.17.16gun

Gundel, Jeanette. 1999. On different kinds of focus. In Peter Bosch \& Rob van der Sandt (eds.), Focus: Linguistic, cognitive, and computational perspectives, 293-305. Cambridge: Cambridge University Press.

Gundel, Jeanette \& Thorstein Fretheim. 2004. Topic and focus. In Lawrence Horn \& Gregory Ward (eds.), Handbook of Pragmatic Theory, 175-196. Oxford: Blackwell. DOI: https://doi.org/10.1002/9780470756959.ch8

Gussenhoven, Carlos. 1983. Focus, mode and the nucleus. Journal of Linguistics 19. 377-417. DOI: https://doi.org/10.1017/S0022226700007799

Gussenhoven, Carlos. 1992. Sentence accents and argument structure. In Iggy Roca (ed.), Thetic Structure: Its role in grammar, 91-106. Berlin: De Gruyter.

Gussenhoven, Carlos. 2004. The Phonology of tone and intonation. Cambridge: Cambridge University Press. DOI: https://doi.org/10.1017/CBO9780511616983

Gussenhoven, Carlos, Bruno H. Repp, A. C. M. (Toni) Rietveld, Willem H. Rump \& Jacques Terken. 1997. The perceptual prominence of fundamental frequency peaks. Journal of the Acoustical Society of America 102. 3009-3022. DOI: https://doi. org $/ 10.1121 / 1.420355$

Gutzmann, Daniel. 2015. Use-conditional meaning. Studies in multidimensional semantics. Oxford: Oxford University Press. DOI: https://doi.org/10.1093/acprof: oso/9780198723820.001.0001

Gutzmann, Daniel. 2019. The Grammar of expressivity. Oxford: Oxford University Press. DOI: https://doi.org/10.1093/oso/9780198812128.001.0001

Hagstrom, Paul. 1998. Decomposing questions. Cambridge, MA: MIT dissertation.

Hagstrom, Paul. 2004. Particle movement in Sinhala and Japanese. In Veneeta Dayal \& Anoop Mahajan (eds.), Clause structure in South Asian languages, 227-52. Dordrecht: Kluwer Academic Publishers. DOI: https://doi.org/10.1007/978-1-4020-2719-2_8

Hajičová, Eva. 1994. Topic/focus and related research. In Philip A. Luelsdorff (ed.), The Prague School of Structural and Functional Linguistics, 245-275. Amsterdam: John Benjamins. DOI: https://doi.org/10.1075/llsee.41.10haj

Halle, Morris \& Alec Marantz. 1993. Distributed Morphology and the pieces of inflection. In Kenneth Hale \& Samuel J. Keyser (eds.), The view from Building 20, 111-176. Cambridge, MA: The MIT Press.

Halle, Morris \& Alec Marantz. 1994. Some key features of Distributed Morphology. In Andrew Carnie \& Heidi Harley (eds.), MIT Working Papers in Linguistics 21: Papers on Phonology and Morphology, 275-288. Cambridge, MA: MITWPL.

Halle, Morris \& Jean Roger Vergnaud. 1987. An Essay on Stress. Cambridge, MA: The MIT Press.

Hamblin, Charles L. 1973. Questions in Montague English. Foundations of Language 10. 41-53. Harley, Heidi. 1995. Subjects, events, and licensing. Cambridge, MA: MIT dissertation.

Harley, Heidi. 2002. Possession and the double object construction. Yearbook of Linguistic Variation 2. 29-68. DOI: https://doi.org/10.1075/livy.2.04har

Hartmann, Katharina \& Malte Zimmermann. 2007. In place - out of place: Focus in Hausa. In Kerstin Schwabe \& Susanne Winkler (eds.), On information structure: Meaning and form, 365-403. Amsterdam: John Benjamins. DOI: https://doi. org/10.1075/la.100.20har 
Hayes, Bruce. 1995. Metrical Stress Theory. Chicago: The University of Chicago Press.

Hayes, Bruce \& Aditi Lahiri. 1991. Bengali intonational phonology. Natural Language and Linguistic Theory 9. 47-96. DOI: https://doi.org/10.1007/BF00133326

Hedberg, Nancy. 1990. Discourse pragmatics and cleft sentences in English. Twin Cities, MN: University of Minnesota dissertation. DOI: https://doi.org/10.1007/BF00133326

Hedberg, Nancy. 2010. The referential status of clefts. Language 76. 891-920. https:// www.jstor.org/stable/417203. DOI: https://doi.org/10.2307/417203

Hedberg, Nancy. 2013. Multiple focus and cleft sentences. In Katharina Hartmann \& Teun Veenstra (eds.), Cleft structures, 227-250. Amsterdam: John Benjamins Publishing Company. DOI: https://doi.org/10.1075/la.208.08hed

Heim, Irene. 1991. Artikel und Definitheit. In Arnim von Stechow \& Dieter Wunderlich (eds.), Semantik/Semantics. An international handbook of contemporary research, 487-535. Berlin: De Gruyter.

Hellmuth, Sam. 2006. Intonational pitch accent distribution in Egyptian Arabic. London: University of London (SOAS) dissertation.

Hellmuth, Sam. 2007. The relationship between Prosodic Structure and pitch accent distribution: Evidence from Egyptian Arabic. The Linguistic Review 24. 289-314. DOI: https://doi.org/10.1515/TLR.2007.011

Horvath, Julia. 2010. "Discourse features", syntactic displacement, and the status of contrast. Lingua 120. 1346-1369. DOI: https://doi.org/10.1016/j.lingua.2008.07. 011

Hualde, José Ignacio, Gorka Elordieta \& Arantzazu Elordieta. 1994. The Basque dialect of Lekeitio (Supplements of Anuario del Seminario de Filología Vasca "Julio de Urquijo" XXXIV). Bilbao \& Donostia-San Sebastián: Universidad del País Vasco \& Diputación Foral de Gipuzkoa.

Hyman, Larry. 2011. Tone: Is it different? In John Goldsmith, Jason Riggle \& Alan Yu (eds.), The handbook of Phonological Theory, $2^{\text {nd }}$ Edition, 197-239. Oxford: Blackwell. DOI: https://doi.org/10.1002/9781444343069.ch7

Hyman, Larry. 2019. Functions of vowel length in language: Phonological, grammatical and pragmatic consequences. Talk delivered to the London Philological Society, February 15. London: SOAS.

Ikawa, Hajime. 1998. On kakarimusubi in Old Japanese. Journal of Japanese Linguistics 16. 1-38. DOI: https://doi.org/10.1515/jjl-1998-0103

Ishihara, Shinichiro. 2007. Major Phrase, focus intonation, and Multiple Spell-Out. The Linguistic Review 24. 137-167. DOI: https://doi.org/10.1515/TLR.2007.006

Ishihara, Shinichiro. 2011. Japanese focus prosody revisited: Freeing focus from prosodic phrasing. Lingua 121. 1870-1889. DOI: https://doi.org/10.1016/j.lingua.2011.06. 008

Ito, Junko \& Armin Mester. 2012. Recursive prosodic phrasing in Japanese. In Toni Borowsky, Shigeto Kawahara, Mariko Sugahara \& Takahito Shinya (eds.), Prosody matters. Essays in honor of Elisabeth Selkirk, 280-203. London: Equinox.

Ito, Junko \& Armin Mester. 2013. Prosodic subcategories in Japanese. Lingua 124. 20-40. DOI: https://doi.org/10.1016/j.lingua.2012.08.016

Ito, Junko \& Armin Mester. 2016. Unaccentedness in Japanese. Linguistic Inquiry 47. 471-526. DOI: https://doi.org/10.1162/LING_a_00219

Jackendoff, Ray S. 1972. Semantic interpretation in Generative Grammar. Cambridge, MA: The MIT Press.

Jaggar, Philipp. 2006. More on in situ WH- and focus constructions in Hausa. In Dymitr Ibriszimow, Henry Tourneux \& Ekkehard Wolff (eds.), Chadic Linguistics/Linguistique Tchadique/Tschadistik, 49-73. Cologne: Rüdiger Köppe. 
Jun, Sun-Ah (ed.). 2005. Prosodic typology I: The phonology of intonation and phrasing. Oxford: Oxford University Press. DOI: https://doi.org/10.1093/acprof: oso/9780199567300.001.0001

Jun, Sun-Ah (ed.). 2014. Prosodic typology II: The phonology of intonation and phrasing. Oxford: Oxford University Press.

Kabagema-Bilan, Elena, Beatriz López-Jiménez \& Hubert Truckenbrodt. 2011. Multiple focus in Mandarin Chinese. Lingua 121. 1890-1905. DOI: https://doi.org/10.1016/j. lingua.2011.02.005

Kager, René. 2001. Rhythmic directionality by positional licensing. Fifth Holland Institute of Linguistics Phonology conference. Rutgers Optimality Archive 514. http://roa.rutgers. edu/files/514-0402/514-0402-KAGER-0-0.PDF

Kahnemuyipour, Arsalan. 2009. The syntax of sentential stress. Oxford: Oxford University Press. DOI: https://doi.org/10.1093/acprof:oso/9780199219230.001.0001

Kaplan, David. 1999. The meaning of 'Ouch' and 'Oops'. Cornell conference on context dependency. Ithaca, NY: Cornell University. Video: https://youtu.be/iaGRLlgPl6w.

Katz, Jonah \& Elisabeth Selkirk. 2011. Contrastive focus vs. discourse-new: Evidence from phonetic prominence in English. Language 87. 771-816. https://www.jstor.org/ stable/41348860. DOI: https://doi.org/10.1353/lan.2011.0076

Katzir, Roni. 2013. A note on contrast. Natural Language Semantics 21. 333-343. DOI: https://doi.org/10.1007/s11050-013-9095-8

Keating, Patricia, Taehong Cho, Cécile Fougeron, and Chai-shune Hsu. 2004. Domaininitial articulatory strengthening in four languages. In John Local, Richard Ogden \& Rosalind Temple (eds.), Papers in Laboratory Phonology 6. 143-161. Cambridge: Cambridge University Press.

Kiparsky, Paul. 2000. Opacity and cyclicity. The Linguistic Review 17. 351-367. DOI: https://doi.org/10.1515/tlir.2000.17.2-4.351

Kishimoto, Hideki. 2018. Sinhala focus concord constructions from a discourse-syntactic perspective. Glossa 3(1). 9. DOI: https://doi.org/10.5334/gjgl.260

Kisseberth, Charles. 1984. Digo tonology. In G. Nick Clements \& John A. Goldsmith (eds.), Studies in Bantu tonology, 105-182. Dordrecht: Foris.

Kratzer, Angelika. 1999. Beyond 'ouch' and 'oops'. Cornell conference on context dependency. Ithaca, NY: Cornell University. https://semanticsarchive.net/Archive/WEwN$\mathrm{GUyO} /$

Kratzer, Angelika. 2004. Interpreting focus: Presupposed or expressive meanings? Theoretical Linguistics 30. 123-136. DOI: https://doi.org/10.1515/thli.2004.002

Kratzer, Angelika \& Elisabeth Selkirk. 2019. New vs. given. In Daniel Altshuler \& Jessica Rett (eds.), The semantics of plurals, focus, degrees, and times. Essays in honor of Roger Schwarzschild, 157-162. Cham: Springer Nature Switzerland. DOI: https://doi. org/10.1007/978-3-030-04438-1_8

Krifka, Manfred. 2008. Basic notions of information structure. Acta Linguistica Hungarica 55. 243-276. DOI: https://doi.org/10.1556/ALing.55.2008.3-4.2

Kučerová, Ivona. 2012. Grammatical marking of givenness. Natural Language Semantics 20. 1-30. DOI: https://doi.org/10.1007/s11050-011-9073-y

Kügler, Frank \& Caroline Féry. 2017. Post-focal downstep in German. Language and Speech 60. 260-288. DOI: https://doi.org/10.1177/0023830916647204

Kula, Nancy C. \& Lee S. Bickmore. 2015. Phrasal phonology in Copperbelt Bemba. Phonology 32. 146-176. DOI: https://doi.org/10.1017/S095267571500007X

Kuroda, Sige-Yuki. 2007. On the syntax of Old Japanese. In Bjarke Frellesvig, Masayoshi Shibatani \& John Charles Smith (eds.), Current issues in the history and structure of Japanese, 263-317. Tokyo: Kurosio Publishers. 
Kusmer, Leland. 2019. Optimal linearization: Prosodic displacement in Khoekhoe and beyond. Amherst, MA: University of Massachusetts dissertation. DOI: https://doi.org/10.7275/ d1w2-fp34

Ladd, Robert D. 1980. The structure of intonational meaning. Evidence from English. Bloomington: Indiana University Press.

Ladd, Robert D. 1996. Intonational phonology. Cambridge: Cambridge University Press.

Ladd, Robert D. 2008. Intonational phonology. Second edition. Cambridge: Cambridge University Press. DOI: https://doi.org/10.1017/CBO9780511808814

Liberman, Mark \& Alan Prince. 1977. On stress and linguistic rhythm. Linguistic Inquiry 8. 249-336.

Martinovič, Martina. 2015. Information structure of copular sentences in Wolof. Selected proceedings of the 44th annual conference on African Linguistics, 165-179. Somerville, MA: Cascadilla.

McCarthy, John J. 2003. OT constraints are categorical. Phonology 20. 75-138. DOI: https://doi.org/10.1017/S0952675703004470

McCarthy, John J. \& Alan Prince. 1995. Faithfulness and reduplicative identity. University of Massachusetts Occasional Papers in Linguistics 18: Papers in Optimality Theory.

McCarthy, John J. \& Alan Prince. 1999. Faithfulness and identity in Prosodic Morphology. In René Kager, Harry van der Hulst \& Wim Zonneveld (eds.), The Prosody-Morphology interface, 218-309. Cambridge: Cambridge University Press. DOI: https://doi.org/10.1017/CBO9780511627729.008

McCready, Elin. 2010. Varieties of conventional implicature. Semantics \& Pragmatics 3(8). 1-57. DOI: https://doi.org/10.3765/sp.3.8

Merchant, Jason. 2001. The syntax of silence. Sluicing, islands and the theory of ellipsis. Oxford: Oxford University Press.

Merchant, Jason. 2019. Ellipsis: A survey of analytical approaches. In Jeroen van Craenenbrouck \& Tanja Temmerman (eds.), The Oxford handbook of ellipsis, 18-46. Oxford: Oxford University Press. DOI: https://doi.org/10.1093/oxfordhb/978019871 2398.013.2

Molnár, Valéria. 2001. Contrast from a contrastive perspective. In Ivana Kruijff-Korbayová \& Mark Steedman (eds.), Information structure, discourse structure and discourse semantics, 99-114. Helsinki: University of Helsinki.

Molnár, Valéria. 2006. On different kinds of contrast. In Valéria Molnár \& Susanne Winkler (eds.), The architecture of focus, 197-233. Berlin: De Gruyter. DOI: https://doi. org/10.1515/9783110922011

Molnár, Valéria \& Susanne Winkler. 2010. Edges and gaps: Contrast at the interfaces. Lingua 120. 1329-1415. DOI: https://doi.org/10.1016/j.lingua.2008.08.010

Myers, Scott. 1997. OCP effects in Optimality Theory. Natural Language and Linguistic Theory 15. 847-892. https://www.jstor.org/stable/4047901. DOI: https://doi. org/10.1023/A:1005875608905

Neeleman, Ad \& Kriszta Szendrői. 2004. Superman sentences. Linguistic Inquiry 35. 149-159. DOI: https://doi.org/10.1162/ling.2004.35.1.149

Nespor, Marina \& Irene Vogel. 1986. Prosodic phonology. Dordrecht: Foris.

Pierrehumbert, Janet. 1980. The phonetics and phonology of English intonation. Cambridge, MA: MIT dissertation.

Pierrehumbert, Janet \& Mary Beckman. 1988. Japanese tone structure. Cambridge, MA: The MIT Press.

Pierrehumbert, Janet \& Julia Hirschberg. 1990. The meaning of intonational contours in the interpretation of discourse. In Philip R. Cohen, Jerry Morgan \& Martha E. Pollack (eds.), Intentions in communication, 271-311. Cambridge, MA: The MIT Press. 
Potts, Christopher. 2005. The logic of conventional implicatures. Oxford: Oxford University Press. DOI: https://doi.org/10.1093/acprof:oso/9780199273829.001.0001

Prince, Alan. 1983. Relating to the grid. Linguistic Inquiry 14. 19-100. https://www.jstor. org/stable/4178311

Prince, Alan \& Paul Smolensky. 1993. Optimality Theory: Constraint interaction in Generative Grammar. Ms. Rutgers University \& University of Colorado at Boulder.

Prince, Ellen. 1978. A comparison of wh-clefts and it-clefts in discourse. Language 54. 883-906. https://www.jstor.org/stable/413238.DOI:https://doi.org/10.2307/413238

Reinhart, Tanya. 2006. Interface strategies: Optimal and costly computations. Cambridge, MA: The MIT Press. DOI: https://doi.org/10.7551/mitpress/3846.001.0001

Rialland, Annie \& Stéphane Robert. 2001. The intonational system of Wolof. Linguistics 39. 893-939. DOI: https://doi.org/10.1515/ling.2001.038

Rizzi, Luigi. 1997. The fine structure of the left periphery. In Liliane Haegeman (ed.), Elements of grammar, 281-337. Dordrecht: Springer. DOI: https://doi.org/10.1007/97894-011-5420-8_7

Roberts, Craige. 1996. Information structure: Towards an integrated formal theory of pragmatics. OSUWPL 49: Papers in Semantics, 91-136.

Roberts, Craige. 2012. Information structure: Towards an integrated formal theory of pragmatics. Semantics \& Pragmatics 5(6). 1-69. DOI: https://doi.org/10.3765/sp.5.6

Rochemont, Michael. 1986. Focus in Generative Grammar. Amsterdam: John Benjamins Publishing Company. DOI: https://doi.org/10.1075/sigla.4

Rochemont, Michael. 2013a. Discourse new, focused, and given. In Johan Brandtler, Valéria Molnár \& Christer Platzack (eds.), Approaches to Hungarian, vol.13 (Papers from the 2011 Lund conference), 199-228. Amsterdam: John Benjamins Publishing Company.

Rochemont, Michael. 2013b. Discourse new, F-marking, and normal stress. Lingua 136. 38-62. DOI: https://doi.org/10.1016/j.lingua.2013.07.016

Rochemont, Michael. 2016. Givenness. In Caroline Féry \& Shinichiro Ishihara (eds.), The Oxford handbook of information structure, 41-63. Oxford: Oxford University Press. DOI: https://doi.org/10.1093/oxfordhb/9780199642670.013.18

Rooth, Mats. 1985. Association with focus. Amherst, MA: University of Massachusetts dissertation.

Rooth, Mats. 1992a. A Theory of focus interpretation. Natural Language Semantics 1. 75-116. DOI: https://doi.org/10.1007/BF02342617

Rooth, Mats. 1992b. Ellipsis redundancy and reduction redundancy. Ms. Stuttgart: Institut für maschinelle Sprachverarbeitung.

Rooth, Mats. 2015. Representing focus scoping over new. Northeastern Linguistic Society (NELS) 45. 1-15.

Rooth, Mats. 2016. Alternative Semantics. In Caroline Féry \& Shinichiro Ishihara (eds.), The Oxford handbook of information structure, 19-40. Oxford: Oxford University Press. DOI: https://doi.org/10.1093/oxfordhb/9780199642670.013.19

Samko, Bern. 2016. Syntax and information structure: The grammar of English inversions. Santa Cruz, CA: University of California dissertation.

Schlenker, Philippe. 2007. Expressive presuppositions. Theoretical Linguistics 33. 237-245. DOI: https://doi.org/10.1515/TL.2007.017

Schmerling, Susan F. 1976. Aspects of English sentence stress. University of Texas Press.

Schwarzschild, Roger. 1993. The contrastiveness of associated foci. Ms. Rutgers University.

Schwarzschild, Roger. 1999. GIVENness, AvoidF and other constraints on the placement of focus. Natural Language Semantics 7. 141-77. DOI: https://doi. org/10.1023/A:1008370902407 
Selkirk, Elisabeth. 1984. Phonology and syntax. The relation between sound and structure. Cambridge, MA: The MIT Press.

Selkirk, Elisabeth. 1995. Sentence prosody: Intonation, stress and phrasing. In John A. Goldsmith (ed.), The handbook of Phonological Theory, 550-569. Oxford: Blackwell.

Selkirk, Elisabeth. 1996. The prosodic structure of function words. In Jerry L. Morgan \& Katherine Demuth (eds.), Signal to syntax: Bootstrapping from speech to grammar in early acquisition, 187-213. Hillsdale: Lawrence Erlbaum Associates.

Selkirk, Elisabeth. 2000. The interaction of constraints on prosodic phrasing. In Merle Horne (ed.), Prosody: Theory and experiment, 281-261. Dordrecht: Kluwer. DOI: https:// doi.org/10.1007/978-94-015-9413-4_9

Selkirk, Elisabeth. 2002. Contrastive FOCUS vs. Presentational Focus: Prosodic evidence from Right Node Raising in English. Speech Prosody 2002. Aix-en-Provence.

Selkirk, Elisabeth. 2007. Bengali intonation revisited: An Optimality Theoretic analysis in which FOCUS stress prominence drives FOCUS phrasing. In Chungmin Lee, Matthew Gordon \& Daniel Büring (eds.), Topic and Focus, 215-244. Dordrecht: Springer. DOI: https://doi.org/10.1007/978-1-4020-4796-1_12

Selkirk, Elisabeth. 2008. Contrastive focus, givenness, and the unmarked status of "discourse-new". Acta Linguistica Hungarica 55. 1-16. https://www.jstor.org/stable/26190911. DOI: https://doi.org/10.1556/ALing.55.2008.3-4.8

Selkirk, Elisabeth. 2009. On Clause and Intonational Phrase in Japanese: The syntactic grounding of prosodic constituent structure. Gengo Kenkyu 136. 35-74.

Selkirk, Elisabeth. 2011. The syntax-phonology interface. In John A. Goldsmith, Jason Riggle \& Alan Yu (eds.), The handbook of Phonological Theory. 2nd Edition, 435-484. Oxford: Wiley. DOI: https://doi.org/10.1002/9781444343069.ch14

Selkirk, Elisabeth \& Seunghun J. Lee (eds.). 2015. Constituency in sentence phonology. Special issue of Phonology 32(1). DOI: https://doi.org/10.1017/S0952675715000 020

Shattuck-Hufnagel, Stefanie \& Alice Turk. 1996. A prosody tutorial for investigators of auditory sentence processing. Journal of Psycholinguistic Research 25. 193-247. DOI: https://doi.org/10.1007/BF01708572

Šimík, Radek \& Marta Wierzba. 2015. The role of givenness, presupposition, and prosody in Czech word order: An experimental study. Semantics and Pragmatics 8(3). 1-103. DOI: https://doi.org/10.3765/sp.8.3

Slade, Benjamin. 2018. History of focus-concord constructions and focus-associated particles in Sinhala, with comparison to Dravidian and Japanese. Glossa 3(1). 2. DOI: https://doi.org/10.5334/gjgl.241

Sugahara, Mariko. 2012. Phonetic evidence for prosodic word prominence. In Toni Borowsky, Shigeto Kawahara, Mariko Sugahara \& Takahito Shinya (eds.), Prosody matters: Essays in honor of Elisabeth Selkirk, 208-231. London: Equinox.

Szabolcsi, Anna. 1981. Compositionality in focus. Folia Linguistica 15. 141-161. DOI: https://doi.org/10.1515/flin.1981.15.1-2.141

Szendrôi, Kriszta. 2001. Focus and the syntax-phonology interface. London: University College London dissertation.

Szendrői, Kriszta. 2017a. Focus movement. In Martin Everaert \& Henk V. Riemsdijk (eds.), The Wiley Blackwell companion to syntax, 2nd edition. Oxford: Wiley. DOI: https://doi. org/10.1002/9781118358733.wbsyncom100

Szendröi, Kriszta. 2017b. The syntax of information structure and the PF interface. Glossa 2(1). 32. DOI: https://doi.org/10.5334/gjgl.140

Tancredi, Christopher. 1992. Deletion, deaccenting, and presupposition. Cambridge, MA: MIT dissertation. 
Torreira, Francisco \& Martine Grice. 2018. Melodic constructions in Spanish: Metrical structure determines the association properties of intonational tones. Journal of the International Phonetic Association 48, special issue 1. 9-32. DOI: https://doi. org/10.1017/S0025100317000603

Torrence, Harold. 2013. A promotion analysis of Wolof clefts. Syntax 16. 176-215. DOI: https://doi.org/10.1111/synt.12000

Truckenbrodt, Hubert. 1995. Phonological phrases - their relation to syntax, focus, and prominence. Cambridge, MA: MIT dissertation.

Truckenbrodt, Hubert. 1999. On the relation between syntactic phrases and phonological phrases. Linguistic Inquiry 30. 219-255. DOI: https://doi. org/10.1162/002438999554048

Truckenbrodt, Hubert. 2002. Upstep and embedded register levels. Phonology 19. 77-120. DOI: https://doi.org/10.1017/S095267570200427X

Truckenbrodt, Hubert. 2004. Final lowering in non-final position. Journal of Phonetics 32. 313-348. DOI: https://doi.org/10.1016/j.wocn.2003.11.001

Truckenbrodt, Hubert. 2006. Phrasal stress. In Keith Brown (ed.), Encyclopedia of Language and Linguistics, 2nd edition, 572-579. Oxford: Elsevier. DOI: https://doi.org/10.1016/ B0-08-044854-2/04447-3

Truckenbrodt, Hubert. 2007a. The syntax-phonology interface. In Paul de Lacy (ed.), The Cambridge handbook of phonology, 435-56. Cambridge: Cambridge University Press. DOI: https://doi.org/10.1017/CBO9780511486371.019

Truckenbrodt, Hubert. 2007b. Upstep of edge tones and of nuclear accents. In Carlos Gussenhoven \& Thomas Riad (eds.), Tones and tunes. Vol. 2: Experimental studies in word and sentence prosody, 349-86. Berlin: De Gruyter Mouton. DOI: https://doi. org/10.1515/9783110207576.2.349

Truckenbrodt, Hubert. 2012a. On the prosody of German wh-questions. In Gorka Elordieta \& Pilar Prieto (eds.), Prosody and meaning, 73-118. Berlin: De Gruyter Mouton.

Truckenbrodt, Hubert. 2012b. Semantics of intonation. In Claudia Maienborn, Klaus von Heusinger \& Paul Portner (eds.), Semantics. An international handbook of natural language meaning. Vol. 3, 2039-2069. Berlin: De Gruyter Mouton.

Truckenbrodt, Hubert. 2016. Focus, intonation, and tonal height. In Caroline Féry \& Shinichiro Ishihara (eds.), The Oxford handbook of information structure, 461-482. Oxford: Oxford University Press. DOI: https://doi.org/10.1093/ oxfordhb/9780199642670.013.44

Vallduví, Enric. 2016. Information structure. In Maria Aloni \& Paul Dekker (eds.), The Cambridge handbook of Formal Semantics, 728-55. Cambridge: Cambridge University Press. DOI: https://doi.org/10.1017/CBO9781139236157.024

Vallduví, Enric \& Maria Vilkuna. 1998. On Rheme and Kontrast. In Peter Culicover \& Louise McNally (eds.), Syntax and Semantics 29. The limits of syntax, 79-108. San Diego: Academic Press. DOI: https://doi.org/10.1163/9789004373167_005

van den Berg, Rob, Carlos Gussenhoven, \& Toni Rietveld. 1992. Downstep in Dutch: Implications for a model. In Gerard J. Docherty \& D. Robert Ladd (eds.), Papers in Laboratory Phonology II: Gesture, segment, prosody, 335-358. Cambridge: Cambridge University Press.

van der Wal, Jenneke. 2016. Diagnosing focus. Studies in Language 40. 259-301. DOI: https://doi.org/10.1075/sl.40.2.01van

Volk, Erez. 2011. Mijikenda tonology. Tel Aviv: Tel Aviv University dissertation.

von Fintel, Kai. 1994. Restrictions on Quantifier Domains. Amherst, MA: University of Massachusetts dissertation. https://scholarworks.umass.edu/dissertations/ AAI9434544 
Wagner, Michael. 2005. Prosody and recursion. Cambridge, MA: MIT dissertation.

Wagner, Michael. 2012. Focus and givenness: A unified approach. In Ivona Kučerová \& Ad Neeleman (eds.), Contrasts and positions in information structure, 102-47. Cambridge: Cambridge University Press. DOI: https://doi.org/10.1017/CBO9780511740084.007

Whitman, John. 1997. Kakarimusubi from a comparative perspective. Japanese/Korean Linguistics 6, Stanford: Center for the Study of Language and Information.

Williams, Edwin. 1997. Blocking and anaphora. Linguistic Inquiry 28. 577-628.

Williams, Edwin. 2012. The locality of focusing and the coherence of anaphora. In Ivona Kučerová \& Ad Neeleman (eds.), Contrasts and positions in information structure, 148-74. Cambridge: Cambridge University Press. DOI: https://doi.org/10.1017/ CBO9780511740084.008

Winkler, Susanne. 2016. Ellipsis and information structure. In Caroline Féry \& Shinichiro Ishihara (eds.), The Oxford handbook of information structure, 359-82. Oxford: Oxford University Press. DOI: https://doi.org/10.1093/oxfordhb/9780199642670.013.31

$\mathrm{Xu}, \mathrm{Yi} .1999$. Effects of tone and focus on the formation and alignment of F0 contours. Journal of Phonetics 27. 55-105. DOI: https://doi.org/10.1006/jpho.1999.0086

Yip, Moira. 2002. Tone. Cambridge: Cambridge University Press. DOI: https://doi. org/10.1017/CBO9780511486371.011

Yip, Moira. 2007. Tone. In Paul de Lacy (ed.), The Cambridge handbook of phonology, 229-251. Cambridge: Cambridge University Press.

Zimmermann, Malte. 2011. The grammatical expression of focus in West Chadic: Variation and uniformity in and across languages. Linguistics 49. 1161-1211. DOI: https://doi.org/10.1515/ling.2011.032

Zubizarreta, María Luisa. 1998. Prosody, focus, and word order. Cambridge, MA: The MIT Press.

Zubizarreta, María Luisa. 2016. Nuclear stress and information structure. In Caroline Féry \& Shinichiro Ishihara (eds.), The Oxford handbook of information structure, 163-84. Oxford: Oxford University Press.

Zubizarreta, María Luisa \& Jean-Roger Vergnaud. 2006. Phrasal stress and syntax. In Martin Everaert \& Henk van Riemsdijk (ed.), The Blackwell companion to syntax, 522-568. Oxford: Blackwell. DOI: https://doi.org/10.1002/9780470996591. $\operatorname{ch} 49$

How to cite this article: Kratzer, Angelika and Elisabeth Selkirk. 2020. Deconstructing information structure. Glossa: a
journal of general linguistics 5(1): 113.1-53. DOI: https://doi.org/10.5334/gigl.968

Submitted: 12 April 2019

Accepted: 26 March 2020

Published: 20 November 2020

Copyright: $\odot 2020$ The Author(s). This is an open-access article distributed under the terms of the Creative Commons Attribution 4.0 International License (CC-BY 4.0), which permits unrestricted use, distribution, and reproduction in any medium, provided the original author and source are credited. See http://creativecommons.org/licenses/by/4.0/.

$\mathrm{u}[\quad$ Glossa: a journal of general linguistics is a peer-reviewed open access journal published by Ubiquity Press. 